\title{
Biology of Cilia and Ciliopathies
}

\author{
David Alejandro Silva, Elizabeth Richey and Hongmin Qin \\ Department of Biology, Texas AEM University, College Station, \\ USA
}

\section{Introduction}

Cilia and flagella are microtubule-based appendages extending from the basal body of most eukaryotic cells, and are classified as either motile or primary. Motile cilia or flagella can be found on many cells such as Chlamydomonas, sperm, and respiratory tract epithelial cells. This type of cilia is responsible for movement of the cell itself or generation of fluid flow. In contrast, primary cilia are non-motile organelles that are critically involved in visual, olfactory and auditory signal transduction and play key roles in the regulation of gene expression, development, and behavior. This chapter reviews the current understanding of the various mechanisms involved in cilia and flagellar assembly and maintenance. Consistent with the nearly ubiquitous cellular distribution, cilia have been implicated in numerous human diseases collectively known as ciliopathies. This chapter also discusses several major ciliopathies including primary ciliary dyskinesia, hydrocephalus, polycystic kidney disease, Bardet-Biedl syndrome, and cancer.

\section{Mechanics of ciliogenesis}

\subsection{Basic biology of cilia}

Cilia and flagella are long, slender structures protruding from the body of ciliated cells and are composed of a microtubule-based core known as the axoneme. The main structural element is an array of nine doublet microtubule pairs. The a-subfiber of these pairs exists as a fully enclosed filament and is fused to the incomplete b-subfiber containing fewer tubulin subunits. The individual pairs of subfibers are linked together by nexin proteins, forming an enclosed cylinder around a central pair of singlet subfibers; this layout is known as the "9+2" arrangement. The axoneme itself originates from the basal body, a modified form of the centriole consisting of nine triplet microtubules which anchors the cilia to the plasma membrane. The area between the triplet microtubules of the basal body and doublet pairs of the axoneme is referred to as the transition zone. Proteinaceous extensions from this area called transition fibers serve to mark the enclosure of the flagellar compartment and create a barrier from the cytoplasm. The outer and inner dyneins, located on the a-subfiber of the axoneme, are motor proteins that produce the bending and sliding of the microtubules by exerting force on the b-subfiber via ATP hydrolysis. Defects in the inner and outer motor complexes can yield paralyzed or uncoordinated sliding of the axoneme, resulting in inefficient movement. The outer doublet ring and the central pair of microtubules are connected by structures known as radial spokes [1]. 
Cilia can be distinguished into two types: primary (nonmotile) and motile cilia. While they have the same basic structure, the biological functions of these two types can be very different. Primary cilia typically do not contain the central pair of microtubules (having a "9+0" structure), and also lack other accessory proteins important for generating the ciliary waveform stroke. This form of cilia is considered a sensory antenna for the cell due to a highly specialized membrane protein profile and ability to extend in the luminal space of various tissues. Historically, motile cilia/flagella are known to be important for locomotion in single-celled organisms. In humans, however, motile cilia are important for various physiological processes, ranging from mucous clearing in the trachea to aiding in establishing proper left-right symmetry in developing organisms [2]. Because of their structural similarities, the terms cilia and flagella will be used interchangeably.

\subsection{Intraflagellar transport at a glance}

Intraflagellar transport (IFT) is a term used to describe the bi-directional movement of nonmembrane protein particles that move along the microtubule doublet core (or axoneme), between the space of the ciliary membrane and the axoneme. IFT was originally discovered by Kozminksi and colleagues in 1993, using digital interference contrast (DIC) microscopy to visualize the continuous movement of "bulges" beneath the membrane of a Chlamydomonas reinhardtii mutant with paralyzed-cilia [3]. Anterograde movement, towards the ciliary tip or plus end of microtubules, is powered by heterotrimeric kinesin-2, and retrograde movement is driven by cytoplasmic dynein1b [4-14]. A multi-meric protein complex known as the IFT particle attaches to the motor complex and is itself comprised of two large protein sub-complexes [5]. The axoneme is undergoing constant turnover at its tip, meaning tubulin and other accessory proteins must be constantly replenished at the distal tip [15]. The well-conserved IFT motors and particles are tasked with assembling and maintaining the whole cilia structure by serving as adaptors for the transport of axonemal precursors and the recycling of turnover products [1]. A secondary, though equally important, function of IFT is to ferry in ciliary membrane proteins through a secondary adapter complex known as the BBSome $[16,17]$.

\subsubsection{IFT Motors}

\subsubsection{Anterograde motor}

First isolated in sea-urchin, the anterograde IFT motor is a heterotrimeric kinesin-2, comprised of three individual subunits [18]. Homologs are found in a variety of ciliated organisms, including Tetrahymena, Caenorhabditis elegans, and humans. In Chlamydomonas, FLA10 and FLA8 comprise the motor portion of the complex and together they interact with FLA3, a kinesin-associated protein [19]. First evidence for the role of the kinesin-2 in anterograde movement came from the characterization of a temperature sensitive mutant in FLA10. While incubated at the permissive temperature $\left(22^{\circ} \mathrm{C}\right)$, the biflagellated green algae possess two, full-length flagella. However, following a shift to the non-permissive temperature $\left(32^{\circ} \mathrm{C}\right)$, FLA10 subunit denatures and levels of IFT proteins significantly reduce within the first hour [6]. Cessation of IFT results in the dismantling of the axoneme and the entire ciliary structure is retracted back into the cell body because of the normal turnover [5]. In addition, an isolated null mutant for the FLA10 subunit produces no flagella [20]. Taken together, these studies demonstrate the importance of kinesin-2 to ciliogenesis. 
These observations, however, are not entirely consistent among all ciliated organisms. Mutations in the kinesin-2 motor subunits of different species do not result in a cilia-less cell phenotype because of a secondary, homodimeric kinesin known as OSM-3 in C. elegans and KIF17 in Homo sapiens[13]. Studies investigating the function of OSM-3 conclude that the canonical kinesin-2 motor and OSM-3 work in a concerted effort to build sensory cilia in C. elegans [13]. Single mutants in KLP-11 (FLA8) and KAP-1 (FLA3) in C. elegans appear to form intact sensory cilia due to the redundancy of OSM-3 function in ciliogenesis (Signor et al, 1999). However, perturbations of OSM-3 results in loss of the ciliary distal segment comprised of singlet microtubule extensions beyond the doublet axoneme core. In these mutants, the heterotrimeric anterograde motor still allows formation of the middle segment.

It could be possible the transferring of the IFT particle from the canonical kinesin-II to OSM3 may insure proper, sequential construction of the cilia. However, it has been well documented that OSM-3 speed actually increases in disrupted kinesin-II mutants [21], suggesting that kinesin-II may in fact be negatively regulating OSM-3. If so, kinesin-II would ultimately be involved in determining the re-supply rate of axonemal precursors to the flagella compartment. Defects in retrograde IFT clearly demonstrate the negative impact that excess precursors and turnover products have on proper ciliary function. Therefore, accumulation of axonemal components, due to a faster influx of proteins by OSM-3, could also unbalance the natural turnover vs. assembly in favor of creating longer cilia, which is a phenotype that has been observed in kinesin-II mutants. Recently, a null mutant for a relatively new kinesin, KLP-6 in C. elegans males, demonstrated a slower procession of OSM3/KAP-1-associated IFT particle within the ciliary compartment [22]. Although it was observed moving independently of the canonical IFT particle/motor complex, KLP-6 function may have a positive influence on ciliary length. This conclusion is supported by a reduction of $k l p-11 / k l p-6$ double mutant cilia compared to the single $k l p-11$ mutant; $k l p-11$ mutant has comparatively longer cilia than wild-type.

\subsubsection{Retrograde motor}

IFT-dynein, cytoplasmic dynein 2 (previously known as dynein 1b), powers the retrograde movement of IFT [12]. To date, four proteins are confirmed members of the dynein 2 complex: heavy chain DHC1b, light chain LC8, light intermediate chain D1bLIC, and an intermediate chain FAP133 [7-9, 14, 23-25]. C. elegans null mutants defective in dynein components undergo normal anterograde movement but accumulate large amounts of IFT proteins and turnover products within the ciliary compartment [26]. Retrograde-defective cilia are severely truncated and contain protein aggregates that appear as noticeable large, electron-dense clots. These results suggest IFT dynein is responsible for the retrograde movement of the IFT; this result has been seen in Chlamyomonas, where defects in IFT dynein lead to protein accumulations in the flagella compartment [27]. Anterograde movement remains active in these mutants; however, the characteristic bulbous cilia are present as a result of axonemal turnover outpacing the dysfunctional retrograde IFT. It has become fairly evident that IFT particles do not passively diffuse out of the flagella compartment and turnover products must be actively removed by dynein 2 in order to allow unhindered trafficking of the IFT trains.

The current model for retrograde activation is fragmented at best. IFT-dynein is carried into the compartment in an inactivated form as part of the IFT cargo. Once it reaches the tip, a 
poorly understood remodeling occurs, initiating the dynein-powered return of the IFT train back to the cell body $[27,28]$. During retrograde movement, the kinesin is inactivated, but it is unknown whether kinesin-2 is removed by the IFT particle as part of the turnover cargo or simply diffused out. IFT-dynein has been historically shown to associate with complex A in Chlamydomonas, primarily due to IFT-A temperature sensitive mutants exhibiting similar phenotypes as retrograde mutants $[29,30]$. During remodeling at the distal tip, IFT-A likely facilitates the activation of dynein- 2 in order to initiate retrograde movement, although a detailed mechanistic overview is lacking [28].

The newest addition to the retrograde movement model suggests OSM-3 and kinesin-II may directly transport IFT dynein, independently of the IFT particle in C. elegans [11]. The conclusion is derived from IFT-dynein undergoing normal IFT transportation speeds despite the uncoupling of IFT complex A/kinesin-2, and complex B/OSM-3. Another new concept suggests IFT172 may in fact mediate the interaction between inactivated dynein and the IFT particle during anterograde movement [28]. A new study in C. elegans has revealed the presence of a new retrograde dynein motor, specific to outer labial quadrant neurons, which are able to form full functional cilia in canonical IFT dynein mutants [11].

\subsubsection{Regulation of the motors}

IFT motor regulation continues to be of high interest in the cilia field due to the motors' important functions. Defects in FLA3, the kinesin associated protein, lead to mislocalized kinesin-II and subsequently produce a bald or flagella-less phenotype in Chlamydomonas [31]. Isolation of DYF-11 null mutant, a homolog of human microtubule-interacting protein (MIP)-T3 and IFT54 in C. elegans, reveals that this protein may serve as an anchoring protein for the priming/loading of the entire IFT motor/particle complex onto the transition zone of cilia [32]. KIF17, OSM-3 homolog of C. elegans, in human primary cilia was discovered to be under the regulation of a RAN gradient between the cell body and flagellar compartment. This mechanism operates in similar fashion to the RAN gradient active in regulating the trafficking of proteins across the nuclear pore complex [33]. A ciliary localization signal (CLS) at the tail end of KIF17 was shown to contribute to the interaction with another accessory protein known as importin- $\beta 2$, a nuclear import protein; this interaction was inhibited by RAN-GTP. Similar CLS signals may exist for additional proteins in other model organisms due to the conserved nature of IFT. Recent study into the regulation of IFT-dynein flagellar entry has suggested that Chlamydomonas IFT172, a peripheral protein of IFT-B subcomplex, may be directly involved in the transport of IFT-dynein into the flagellar compartment [28].

\subsection{IFT particle}

By comparing the flagellar proteome of a fla10ts mutant after incubation at the nonpermissive temperature to a wild-type proteome, Cole and colleagues biochemically observed the depletion of certain proteins from the flagellar compartment [5]. After further analysis, members of the IFT particle were discovered. Results from this study demonstrated that the IFT particle was actually comprised of two sub-complexes, IFT-A and IFT-B, which to date consist of 6 and 12 polypeptides, respectively [19]. A recent study shed new light on the organization of the IFT-B subcomplex, demonstrating it can be separated further into two tetrameric subdomains: IFT25/27/74/81/72 and IFT52/46/88/70 [34-36]. 
IFT52 serves as the interface between the IFT74/81 and IFT52/46/88/70 [36]; IFT74/81 functions as the intermediate complex between IFT25/27 and IFT52/46/88/70. Currently IFT-A complex is understood to be composed of IFT144/121/140/121/139/43 [30], however its structural organization remains unclear.

A majority of the IFT members are enriched in WD40 and tetracopeptide repeats (TPR), multi-protein binding domains that possibly form a circularized beta-propeller structure and alpha helical solenoid, respectively, to behave as scaffolding elements [19]. WAA is another binding motif present in these proteins, although it is poorly understood. Most of the IFT proteins contribute to the overall integrity of their respective complexes, evident by the subsequent instability and depletion of complex-mates following disruption of certain IFT proteins. Depending on which complex is disrupted, flagella morphology is typically affected in one of two ways: structurally sound but severely truncated cilia (IFT-B mutants) or short bulbous flagella (IFT-A) $[1,13,27]$. The resulting phenotype reveals the different nature of the two complexes; short flagella convey IFT-B's importance in anterograde movement and protein buildup in the flagella compartment suggest IFT-A is involved in retrograde IFT. Nonetheless, the many parts of IFT machinery must work in a concerted effort to strike an efficient balance between retrograde and anterograde transportation dynamics.

Defects in other IFT-B proteins typically lead to a bald phenotype, making any biochemical analysis a challenge to determine individual function. A null mutant of ift88, the first IFT protein to be implicated in disease [37], displays a bald phenotype in Chlamydomonas. The absence of IFT54/MIP-T3 causes the entire IFT motor/particle complex, with the exception of OSM-3, to mislocalize at the ciliary base in C. elegans [32]. In IFT46 mutants, IFT-B complex still assembles the complex B core proteins but stability is severely affected, evident by the presence of structural sound yet short flagella in Chlamydomonas [38]. A suppressor IFT46 mutant sufficiently stabilizes the IFT complex to produced full length flagella. However, upon closer analysis, the axoneme lack outer dynein arms [38]. Thus, IFT46 serves as an adaptor protein for the specific transport of ODA16, a component of the outer dynein arms [39]. It is unclear whether IFT46 functions as a structural protein, since it appears not to be an essential contributor to complex B structural integrity (Richey and Qin, unpublished). It could possess a secondary function as a molecular indicator or chaperone for the IFT-B complex assembly, since the IFT-B can still assemble on a sucrose density gradient (Richey and Qin, unpublished). In addition to the known IFT core proteins, there are a few peripheral proteins associated with complex B: IFT57, IFT20, IFT172, and IFT80 [34]. IFT20 is a particularly interesting protein, because it is the only IFT protein that can localize in the Golgi apparatus, the central hub for the sorting and packaging of macromolecules for secretion. The current model suggests IFT20 is involved in directing vesicles transporting ciliary-specific proteins near the basal body, and participating in the trafficking of membrane proteins into the flagellar compartment [40]. IFT57 can target to the transition fibers of the axoneme, and serves as an anchoring protein for IFT20 to IFT-B in zebrafish [41]. IFT172 is also an interesting protein, since it readily dissociates from the IFT particle and has been shown to be important for retrograde movement. Using temperature sensitive mutant fla11ts (IFT172), Pederson et al. 2006 concluded that IFT172 directly interacts with CrEB1, a protein exclusively located at the flagella tip, and accumulates IFT-B but not IFT-A nor IFT dynein proteins in the flagella [42, 43]. Recently, evidence of IFT172 involvement in the flagellar entry of IFT-dynein was detected in Chlamydomonas. Upon 
incubation at the non-permissive temperature, IFT-dynein is depleted from the flagella compartment of the temperature sensitive IFT172 mutant while the rest of IFT particle remains at wild-type levels [28].

The function of individual IFT-A sub-complex proteins are even more enigmatic. Much like IFT-B proteins, disruption or depletion of a single IFT-A protein leads to the instability of the complex and subsequent depletion from the cell body [28]. Mouse IFT122 was shown to regulate members of the sonic hedgehog pathway in a number of ways by uniquely affecting the localization of certain proteins differently than IFT-A and IFT dynein mutants [44]. In Drosophila, an IFT140 mutant does not have detectable levels of ciliary TRPV ion channels; while the mRNA levels were unchanged, IFT140 may instead be important for the post-translational stability of the ion channels [45]. The more predominant understanding of the IFT-A function comes from its importance to retrograde movement. At the permissive temperature, electron-dense bulges are present within the cilia of temperaturesensitive Chlamydomonas mutants in IFT139 (fla17) and IFT144 (fla15). Following a shift to the non-permissive temperature leads to the complete breakdown of retrograde IFT and retraction of the axoneme, resulting in lolli-pop shaped bulbs filled with IFT-B proteins [29, 30]. This phenotype is also observed in IFT dynein mutants, thought to arise from the possible hindrance of retrograde IFT activation, and ultimately leading to the buildup of turnover products and IFT particles within the flagellar compartment [43]. In C. elegans, IFT-A directly interacts with kinesin-II while IFT-B is transported by OSM-3. IFT-A and IFT$\mathrm{B}$ are linked together by the BBSome, a secondary adaptor complex important for ciliary membrane biogenesis [21, 46].

\subsection{BBSome role in membrane biogenesis}

Originally discovered during genetic disease screens, the BBSome protein complex functions as an adaptor complex for the IFT particle and facilitates the transport of ciliary membrane proteins. Interaction assays using BBS4 led to the discovery of the seven conserved proteins, BBS1/2/4/5/7/8/9, that comprise the BBSome complex [47]. In the same study, BBS5 was found to interact with phosphoinositides, phospholipids important for recruitment of trafficking proteins to the plasma membrane, implicating a role for the BBSome in vesicle trafficking. In addition, the BBS1 was shown to interact with Rabin8, a guanine nucleotide exchange factor (GEF) for Rab8, two proteins important for ciliary protein trafficking [16]. BBS1 direct association with Rabin8 stimulates the protein's GEF-activity to promote Rab8 activation. Rab8 and Rabin8 contribution to ciliogenesis will be discussed below. Arl6 (BBS3), although not important for BBSome assembly, is important for the recruitment of BBSome to primary cilia and purified liposomes [48]. In Chlamydomonas, perturbation of BBSome proteins does not lead to any morphological defects; however, cells are unable to undergo phototaxis, suggesting a role in signal transduction. The ciliary membrane in BBS1, BBS4, and BBS7 mutants accumulate several proteins which are thought to hinder Ca2+ signaling pathways involved in the phototaxic response [17]. In C. elegans, the BBSome serves as a linking bridge between IFT-A/kinesin-II and IFT-B/OSM-3; disruption of the complex results in the uncoupling of the IFT machinery and leads to cilia morphology defects in some cases [21,46]. Protein models predict the BBSome functions as a vesicle coat, much like clathrin and COPI/II coat, directing post trans-Golgi network (TGN) vesicles to the ciliary compartment and accompanying them as a mediator between the IFT machinery [48]. The BBSome also sporadically "falls off" the IFT train, possibly in the event 
of cargo unloading [17]. However, only a few ciliary membrane proteins have been confirmed to be BBSome-dependent for proper localization, most notably Somatostatin receptor 3 (SSTR30) and some G-coupled receptors. Thus, it is unclear whether the BBSomedependent ciliary transport is a general mechanism or a protein-specific system [17].

\subsection{Role of GTPases in ciliogenesis}

Research in small GTPases involved in ciliogenesis is a growing branch of the field and the results have been quite interesting. ADP-ribosylating factor-like (ARL) 13, BBS3 and the BBSome are involved in the targeting and entry of flagellar membrane proteins into the compartment [16]. ARL-13 and ARL-3 are small G-proteins antagonistically operating to maintain the stability of IFT particles during middle segment transport in C. elegans (IFT A and B) $[49,50]$. ARL-13 may also have roles involved in maintaining axonemal integrity since null mutant animals have a variety of gross cilia abnormalities [49-51]. It has been suggested that ARL13 may in fact regulate the coupling of IFT-A and IFT-B, while ARL3 regulates IFT-B interaction with OSM-3; together they regulate the integrity of the IFT machinery in C. elegans [50]. Rab8 is recruited to the transition zone by Rabin8 (Rab8GEF), following stimulation from BBS1, a core member of the BBSome; this ultimately results in the fusion of post-Golgi vesicles shuttling ciliary membrane proteins near the basal body $[52,53]$. Dominant negative and constitutive active constructs demonstrate the impact that the nucleotide state of Rab8 has on its entry into the ciliary compartment and its role in ciliogenesis [47]. Arf4 and Rab11 form a complex with Arf GTPase activating protein ASAP1 and FIP3 to package and transport rhodopsin from the trans-golgi-network to photoreceptor cilia [54]. This interaction between rhodopsin and Arf4 is dependent on a VxPx motif, a ciliary localization signal also found in other ciliary membrane proteins [16]. Recently, the VxPx motif has been shown to be essential for the trafficking of polycistin-1 protein, and to be involved in the recruitment of Rab8, thereby promoting fusion of ciliary membrane protein-containing vesicles [55]. Another small GTPase, Rab23, was found to be responsible for the turnover of sonic hedgehog signaling protein, Smoothened, from the ciliary compartment [56]. As mentioned in IFT motor regulation section, a RAN-GTP ciliary/cytoplasmic gradient regulates the entry of kinesin motor KIF17 in the primary cilia of cultured cells [33].

Two mysterious members of the IFT-B complex, IFT27/RABL4 and IFT22/RABL5, are the only small GTPases known to directly interact with the IFT particle. IFT25 is a phosphoprotein of unknown function, though it is known to interact with the small GTPase-like IFT27 [57]. Recent work on IFT27 confirmed its GTP binding and GTPase activity along with solving the crystal structure of the sub-complex IFT25/27. However, the exact function of IFT25/27 remains unknown [58]. IFT22 has been the more controversial of the two, since in recent studies with C. elegans and Trypanosome IFT22 homologs produced conflicting results. In C. elegans, a putative constitutive active form (GTP-locked) of the IFTA-2 (IFT22 homolog) can enter the ciliary compartment while dominant negative (GDPlocked) diffusely localizes throughout the neuronal cell body and is notably excluded from the ciliary compartment [59]. IFTA-2 null mutants exhibited extended lifespans, reminiscent of insulin IGF-1-like signaling pathway defects, and a failure to enter dauer formation, a type of survival mode. The null IFTA-2 (IFT22) mutant had intact sensory cilia, effectively suggesting IFTA-2 is not essential to ciliogenesis. However, RNAi knockdown experiments of Trypanosome RABL5 lead to the buildup of IFT particles in the flagella compartment and 
subsequent shortening of the flagella [60]. This phenotype is similar to mutants with defective retrograde IFT, suggesting RABL5 is important for ciliogenesis.

\subsection{Gating the ciliary compartment}

As mentioned above, the transition fibers mark the entrance of the flagella compartment by tethering the plasma membrane to the base of the flagella. The ciliary proteome contains various proteins not found at such concentrated levels in cytoplasm, implying an inherent selectivity to the transition zone barrier [61]. Although the complete regulatory pathway remains poorly understood, various studies have begun to demonstrate the complexity of the flagella gating mechanism. Recent biochemical characterization of cep290 mutant in Chlamydomonas revealed that the protein CEP290 functions as an intricate member of the transition zone barrier proteins [62]. CEP290 is part of the MKS/MKSR/NPHP proteins (Meckel-Gruber syndrome/related and nephronophthisis), shown to localize at the base of the flagella. Together these proteins form the transition zone and function as the ciliary selective barrier, evident by the accumulation of non-ciliary proteins in the cilia of various TZ mutants [63, 64]. Although IFT anterograde movement was normal and retrograde slightly slower, the cep290 flagella accumulated IFT-B proteins and BBS4, yet had a reduction of IFT-A, some membrane proteins and axonemal precursors. This phenotype suggests CEP290 plays a role in the mechanical selectivity of the transition zone; it could be possible that IFT-B binding/priming at the transition zone requires CEP290, which could explain the mostly unhindered movement of IFT and the buildup of IFT-B and not IFT-A.

Additional selectivity mechanisms have become more apparent, such as the requirement of ciliary transport signal (CTS) for access to the flagella compartment [16]. The VxPx motif, a CTS, is important for the targeting and entry of ciliary membrane proteins polycistin- 1 and rhodopsin. In contrast, a recent study discovered a mechanism for molecular retention, whereby passive diffusion into the ciliary membrane is inhibited by a transferable retention signal [65]. Podoclayxin was shown to contain a four- amino acid PDZ binding motif that facilitated its interaction with $\mathrm{NA}+/ \mathrm{H}+$ exchanger 3 regulatory factor NHERF1, a protein attached to the apical actin cytoskeleton [66]. The conserved four- amino acid sequence in the PDZ binding motif was shown to be sufficient to prevent passive diffusion into the cilary membrane domain [65]. Although the ciliary entry is passive, the ciliary membrane protein retention appears to require the protein to be firmly attached to the axoneme. Thus, a ciliary retention signal is likely to be necessary for membrane protein accumulation in the ciliary compartment. Additionally, much like the gating system for the nuclear pore complex, a RAN-GTP has been found to exist between the cilia and cytosol that is important for import of KIF17, via its Ran-GTP dependent association with importin- $\beta 2$ [33].

\subsection{Microtubule post translational modifications}

The microtubule component of the axoneme undergoes various post-translational modifications (PTMs) that play a vital role in promoting the mechanical movement of the organelle. The dramatic impact of microtubule PTMs has been well characterized, but recent studies have begun to deepen our understanding of how PTMs affect ciliary assembly and maintenance. For an extensive review on the impact of PTMs on ciliogenesis and cell motility, please see a recent review by Wloga and Gaertig [67, 68]. 


\subsubsection{Acetylation of tubulin}

$\mathrm{N}$-Acetylation is the only PTM that occurs within the microtubule core, at the highly conserved K40 residue on a-tubulin [69-71]. Mammalian microtubules undergo acetylation of lysine residues on multiple sites located on both a- and $\beta$ - tubulin [72]. Recently MEC17, a previously uncharacterized protein now known as aTAT1 (a-tubulin acetyltransferase), may be the sole enzyme responsible for the acetylation of $\mathrm{K} 40$ in mammalian cilia [73]. Knockdown of aTAT1 does not produce any severe morphological defects nor does it affect microtubule polymerization. However, as a BBSome-associated protein, it was suspected to be involved in cilia assembly. The depletion of aTAT1 leads to a delayed assembly of primary cilia; taken together with recent information, K40 acetylation may be involved in the dynamics of axonemal assembly and disassembly [74]. Recent studies demonstrate that acetylation of a-tubulin may target these subunits for degradation, since they are preferentially selected to be ubiquitinated over $\beta$-tubulin during disassembly [75]. A newly discovered BBSome subunit, BBIP10, functions as a positive regulator of microtubule stability, as a reduction of cytoplasmic microtubules and increase in free tubulin is seen in BBIP10-depleted cells. In addition, overexpression of BBIP10, microtubule acetylation was dramatically increased. The function of BBIP10 on microtubule stability appears to be either dependent or independent of the BBSome [76]

\subsubsection{Glutamylation and glycylation}

Glutamylation has been observed on microtubules in general, while glycylation has been found to be restricted to the ciliary microtubules of flagellated cell types [77]. These side chains are synthesized in distinct steps of initiation and elongation, typically carried out by two types of enzymes known as tyroslytubulin ligase-like proteins (TTLLs) [78, 79]. Recent studies have begun to investigate the function of these types of PTMs for ciliogenesis, most notably by the impact of polyglutamylation on inner dynein dynamics [80, 81].

\section{Ciliopathies}

Ciliated cells can be found in various tissues throughout the human body. These include the eye, the trachea, the kidney, the reproductive tract, the intestines, the heart, and many others. In each of these tissues, the cilia perform a significant role in allowing proper function of the tissues. Since ciliated cells are in most important organ tissues, malfunctioning cilia contribute substantially to human disease. Diseases caused or related to faulty cilia are called ciliopathies. The list of ciliopathies is just as diverse as the variety of tissues in which cilia are found. These diseases support the fact that cilia, once thought to be unimportant cellular appendages, are essential for sustaining health in the human body. There are too many ciliopathies to mention, and the list continues to grow. Some major ciliopathies include Primary Ciliary Dyskinesia (PCD), Hydrocephalus, Polycystic Kidney Disease (PKD), Bardet-Biedl Syndrome (BBS), and even cancer [82].

\subsection{Primary Ciliary Dyskinesia (PCD)}

The relationship between Primary Ciliary Dyskinesia (PCD) and ciliary defects was first discovered in the 1970's [83], making PCD the first human disorder found to be linked to cilia function [84]. PCD is a multi-symptomatic ciliopathy that is present in all major ethnic 
groups and occurs 1 in every 20,000 live births, although this is likely an underestimation due to a failure to properly diagnose the disorder $[85,86]$. PCD was first called "immotile cilia syndrome," but was renamed because it was later found that the cilia were not always immotile, but often had abnormal motility [87].

PCD is characterized by many symptoms that are expressed to various degrees [84]. It affects mainly the respiratory system beginning at birth or within the first month of life. Early signs typically involve a persistent cough and chronic nasal congestion. Other symptoms often include other respiratory problems such as sinusitis and bronchiectasis [87]. The respiratory symptoms of PCD are caused by the lack of uniform ciliary movement to transport particles, or mucous in or out of the organs or the cells themselves. There are about 200 motile cilia in the respiratory tract of a healthy individual. Beating coordinately, these cilia function to remove mucous and debris from the airway in a process called mucocilliary clearance [88]. When the cilia malfunction, there is buildup of mucous and debris in the tract, which leads to respiratory difficulties.

However, this disease is not only associated with the respiratory system. It also has an impact in development, fertility, and aural health. Fifty percent of patients with PCD have total situs inversus, with organs developing on the opposite side of the body. This is thought to be due to the importance of cilia in producing correct direction of nodal flow during embryo development. This was seen in a 2002 study which showed that when direction of nodal flow was artificially reversed to right instead of left, mice developed organs that were a mirror image to normal orientation [89]. There are three known genes involved in left-right axis (LRA) determination, including lrd (left-right dynein), hfh-4 (hepatocyte nuclear factor/forkhead homologue 4), and kif3B (kinesin member 3B) [90-92]. PCD also affects fertility. Males with PCD are typically infertile, and females have a higher rate of ectopic pregnancies. Significant hearing impairment is seen in about fifty percent of children with PCD [93]. This is likely due to the condition known as chronic secretory otitis, which is found almost universally in PCD patients [94]. This is a condition that causes collection of fluid in the middle ear and can cause serious hearing loss and pain. Studies have been done to show that people with chronic secretory otitis have a slower ciliary beat frequency, resulting in failure to move fluid out of the ear canal, leading to infection [95].

PCD is a genetically heterogeneous disease typically caused by autosomal recessive mutations in ciliary protein genes. The most common mutations occur in DNAH5 (dynein heavy chain) and DNAI1 (intermediate chain dynein) genes. Studies show that the disease is caused by abnormalities in the axonemal structure of the cilia. In most patients, the outer dynein arms are missing, of which fifty percent of these patients have mutations in DNAH5 and DNAI1 [96-98]. However, it is thought that lacking the inner dynein arms, central pair of microtubules, or radial spokes can also lead to PCD. Seventy to eighty percent of patients have outer or inner dynein arm defects, while only five to ten percent are missing radial spokes. PCD can also be caused by a disorientation of cilia and transposed microtubules [85]. Transposed microtubules occur when a cilium lacks the central microtubule pair and a peripheral doublet with dynein arms transposes to the center of the axoneme. This microtubule defect, coined "central microtubule agenesis," causes a circular rotation of the cilia rather than the normal back and forth motion [99]. In addition to genetic causation, PCD can also be a result of acquired defects caused by epithelial damage by chronic infection or irritant exposure [100]. 
Beat frequency, beat patterns, and protein localization are all parameters measured in diagnosis of the disease. Nasal brush biopsies are most commonly used to collect a patient's cells, but bronchoscopic brush biopsies can also be used [101]. Typically, a diagnosis is made by examining fixed cells under a transmission electron microscope to identify ciliary structural defects in addition to measuring ciliary beat frequency in live cells by video microscopy. However, in the case of central microtubule agenesis, it is important to also look at ciliary beat pattern, since the cilia typically maintain a normal beat frequency, with aberrant movement. These patients also tend to have normally functioning nodal cilia, which allow normal situs, accounting for the fact that not all PCD patients have situs inversus [99]. This may pose a problem for diagnosis if doctors are using organ orientation as a diagnostic factor. Protein localization is a relatively new and uncommon means of diagnosis. In respiratory cells, certain ciliary proteins have been shown to mislocalize in the case of PCD. These include DNAH5 and DNAI1, which under normal circumstances, colocalize throughout the axoneme. In patients with PCD caused by a mutation in the DNAI1 gene, the protein fails to localize to the distal tip, leading to abnormal motility. In patients with a mutation in DNAH5, the protein is entirely absent from the axoneme, causing complete paralysis. This is useful for diagnosis since immunofluorescence can show if this mislocalization is present [102]. Genetic testing can also be done, but is not very reliable since the disease is very genetically heterogeneous, with the discovery of at least ten related genes from various loci on multiple chromosomes [103]. False positive diagnoses can occur during or after a respiratory infection or inflammation, since these conditions show impaired ciliary function. Therefore diagnosis is only accurate at least four to six weeks post-infection [101].

Screening for the disease is also very important to help rule PCD out for patients with similar symptoms. Among the screening techniques, measuring levels of nasal nitric oxide (nNO) is relatively new but fairly promising. Very low levels of nNO are exhaled from patients with PCD. Therefore, if the patient has high or normal levels, they likely do not have PCD. Levels are not diagnostic of PCD, however, since low levels can also be found in accordance with other diseases such as cystic fibrosis, chronic sinusitis, and others. One downfall of this screening technique is that it is ineffective for children under five years old, since younger children will not be able to blow into the apparatus [104]. Saccharin testing is also used for PCD screening. This is a measurement of the time it takes for a patient to be able to taste saccharin, which is related to the function of the cilia in the taste bud cells. However, this is not a very useful test since it is unreliable in children under twelve. Radioaerosol mucociliary clearance testing, which measures how well mucous is removed from the respiratory tract, is useful in infants for screening, but again is not diagnostic of PCD [101].

Current treatment for PCD is mainly focused on treating and preventing the symptoms of the disease. Studies are being done to test the efficacy of antibiotics, airway clearance, and anti-inflammatory treatments [101]. Nebulized DNase has also shown promise in a 1999 case study with a PCD patient. The patient's symptoms were not relieved from treatment with antibiotic and bronchodilator treatments alone. However, when DNase was used in addition to these treatments, there was a significant improvement in symptoms overnight. This showed the therapeutic potential of DNase, but more studies need to be done to further test the efficacy [105]. Gene therapy is also being considered. A 2010 pilot study showed that a lentiviral vector can incorporate ciliary protein into the axoneme to restore ciliary 
function [96]. Further studies need to be done to make these treatments more mainstream. In addition to treatments, preventative measures such as avoiding respiratory irritations and exercising, can be very helpful. If treatments and preventative measures are unsuccessful, it is often necessary to undergo surgery.

PCD research has taught us a lot about cilia. It has shown the importance of cilia in development, in respiratory function, in aural health, and in fertility. It has also taught us a lot about the structure of cilia and the function of various ciliary proteins. In fact, a 2010 study revealed 208 potential ciliary genes based on PCD research [106]. PCD will continue to give us new insights on ciliary function and will continue to be an important area of ciliopathy research.

\subsection{Hydrocephalus}

Hydrocephalus is a disease in which cerebral spinal fluid (CSF) accumulates in the brain. CSF is mostly produced by the choroid plexuses of the lateral, third, and fourth ventricles [107]. To maintain equilibrium it is important for the excess fluid to drain into the subarachnoid space where it is resorbed into the venous system [108]. When this process malfunctions, the fluid builds up, causing swelling in the brain that leads to many complications. The disease dates back to the time of Hippocrates when he described a "liquefaction of the brain" that showed symptoms such as headache, vomiting, and visual impairment [109]. Other symptoms can include high intracranial pressure, in addition to impairments in gait, cognition, alertness, and continence [110]. Although this disease can have various causes, it has been shown that there is a higher prevalence of hydrocephalus in patients that are known to have ciliary defects, and the disease can also be linked to genes known to impact cilia function or structure [111]. Hydrocephalus is often seen in conjunction with other ciliopathies such as PKD as seen in the Tg737 mouse [112] and more rarely in PCD [113].

Although hydrocephalus has a rich history in research, the disease as a ciliopathy is a relatively new area of study, and much is yet to be learned about its link with cilia. In animal models, 43 mutations from 9 different genes are known to be related to hydrocephalus. In contrast, there is only one gene that has been identified in humans [114]. X-linked hydrocephalus is caused by a mutation in the neural cell adhesion molecule L1 (L1CAM) gene [115]. This form of the disease was first discovered in 1949 [116] and occurs about 1 in every 30,000 male births [117]. No research has been done up to this point to determine if there is a link between L1CAM and cilia.

Many mouse models, however, have allowed identification of multiple ciliary genes that, when mutated, can lead to hydrocephalus. Accumulation of CSF can be caused by malfunctions in CSF production, CSF flow, or CSF absorption. Tg737 mice are missing intraflagellar transport protein IFT88/Polaris. This protein is important for ion transport and the mutation shows an overproduction of CSF, leading to the development of hydrocephalus [107]. This suggests the importance of cilia in signaling and regulation of CSF levels. Mice with this mutation also have abnormal beating of the motile cilia of the ependymal cells, disrupting the CSF flow. However, this is not causal in this case since development of the disease occurs before the motile cilia form [107]. In contrast, CSF flow disruption seems to be the cause of hydrocephalus in Mdnah5 (axonemal dynein heavy chain) and Hydin mutants. These mutants cause structural defects in the axoneme of the 
cilia, leading to impaired motility [111, 118-120]. In these two mutants, the cilia are unable to create sufficient flow to remove CSF from the ventricles. Other hydrocephalus mutants are thought to be linked to important development pathways that may disrupt the CSF equilibrium. Inactivation of Pten and $\beta$-catenin leads to hydrocephalus [121]. These proteins are key players in Wnt signaling pathway and important for proper midbrain development, in which the function of primary cilia could be involved [122]. Polycystin-1, a ciliary membrane protein, is also shown to be important in development and regulating fluid in the brain [112]. Ptch1 and parkin-qk1 mutations also lead to hydrocephalus [123] most likely due to a disruption in the Hedgehog pathway, which also involves the primary cilia [124]. All these findings show the importance of cilia in signaling, development, and movement of fluid, and their roles in maintaining a healthy CSF balance in the brain.

An early method of diagnosis required ventricular puncture to test for dilation and occlusive lesions. This procedure was risky, so it was eventually replaced by computed tomography (CT) and magnetic resonance imaging (MRI) [109]. Prenatal diagnosis can be done for $x$-linked recessive hydrocephalus by doing serial ultrasound scans to test for abnormal growth of the baby's head [125]. Since there is only one known human hydrocephalus gene, and it is for the rare $\mathrm{x}$-linked type, genetic testing is not yet useful for diagnosis.

The oldest treatment known for hydrocephalus was to tightly bandage the baby's deformed swollen head to decrease the size and swelling. This method was abandoned since it increased the intracranial pressure. In the 18th and 19th centuries, special diets were recommended and dehydration was induced with laxatives, diuretics, potassium iodide, etc. In 1957 acetazolamide was first used in practice and is still used to reduce production of CSF. Other treatments were abandoned such as isosorbide and irradiation of the choroid plexus [109]. Vasoconstrictors such as dihydroergotamine have shown promise in allowing better arterial pulsation and reducing ventricular dilation [126]. Various surgical treatments have been used including external CSF drainage, serial lumbar puncturing, and implantation of an internal shunt, which is a catheter that allows drainage of CSF out of the ventricles. These surgical procedures brought about complications such as infections, improper placement of shunts, and hydraulic mismanagement due to body positioning. These complications necessitated further research and improvements. One of the most pivotal improvements is the development and modification of shunts with adjustable, autoregulating, antisiphon, and gravitational valves. There are currently at least 127 designs of valves and more than 20 shunting procedures that have been suggested, with ventriculoperitoneal shunts being the most commonly utilized. Valved shunts are now standard treatment for hydrocephalus, being the choice treatment for about $80 \%$ of cases $[109,127]$. In elderly patients shunt implantation is very risky. Repeated lumbar puncturing in patients with communicating hydrocephalus can potentially prevent the need for shunt surgery in these patients [110]. The newest addition to shunt technology is antibiotic-impregnated shunts that help prevent post-surgical infections [128].

The relationship between cilia and hydrocephalus and the genes that are involved are poorly understood in humans. Advancements in this knowledge may eventually lead to better, less invasive forms of treatment and a better understanding of how cilia function in the brain. 


\subsection{Polycystic Kidney Disease (PKD)}

There are two types of PKD, autosomal dominant polycystic kidney disease (ADPKD) and autosomal recessive polycystic kidney disease (ARPKD). ADPKD is the most common of all the potentially lethal autosomal dominant diseases, with an incidence of 1 in 1000 [129]. Symptoms typically do not present themselves until between the ages of 35-50 years. These symptoms include acute abdominal and lower back pain, hypertension, palpable kidneys, recurrent urinary tract infections, shortness of breath, early satiety, hydrocephalus, kidney stones and cysts in the kidney, liver, thyroid, subarachnoid space, and seminal vesicles [130]. ADPKD most often ends in end stage renal disease (ESRD) between 55 and 75 years old [82]. ARPKD, on the other hand presents itself immediately. Although delayed presentation is possible, ARPKD can often be seen in utero, and leads to ESRD in the neonatal stage and infants often die due to respiratory complications. Also unlike ADPKD, there is usually no cyst formation in other organs in the case of ARPKD [130]. It is also much more rare, with an incidence of 1 in 20000, and has a very high infant mortality rate [131].

Although other factors may be involved, strong correlations have been made between PKD and cilia function. Primary cilia are now known to act as mechanosensors that regulate $\mathrm{Ca}^{2+}$ influx. Fluid flow in the kidney causes the primary cilia to bend, which allows the $\mathrm{Ca}^{2+}$ channels to open, allowing increased intracellular $\mathrm{Ca}^{2+}$. This process is disrupted in some forms of PKD. However, primary cilia have also been implicated in pathways such as Hedgehog, Wnt, cAMP, and Planar Cell Polarity. Disruptions of these pathways can lead to abnormal polarity, differentiation, and proliferation, which can lead to cyst formation [130]. Therefore the role of primary cilia in cystogenesis is not only important, but is very multidimensional.

In human, ADPKD is caused by a mutation in PKD1 (85\% of the time) or PKD2 (15\% of the time). There are more than 500 mutations known in PKD1 and 120 in PKD2 [132, 133]. These genes code for proteins polycystin-1 and polycystin-2, which both localize to renal cilia [134]. These proteins prove to be important in renal tube development and cell differentiation in the kidney. They are involved in the calcium signal transduction cascade that regulates proliferation and differentiation $[135,136]$. ARPKD is caused by a mutation in PKHD1, which encodes fibrocystin, a receptor-like protein associated with the membrane and colocalizes with polycystin-2 in primary cilia [82,137]. It also plays a role in collecting duct and biliary cell differentiation [138]. Studies in other species have made other connections between cilia and PKD. In addition to hydrocephalus, Tg737 mice have cysts in kidney and pancreas, hepatic fibrosis, and polydactyly. Mice with this mutation have elevated polycystin-2 levels and have cilia that are much shorter than normal [135, 139]. These factors result in cyst formation. A mutation in Kif3A (a subunit of kinesin-II in kidney epithelium) causes increased canonical Wnt activity. Deletion of this gene leads to absence of cilia, and after the cilia are lost, cystogenesis occurs [140]. Seahorse is another mutation that shows a disruption in Wnt signaling in zebrafish and may function downstream from cilia [141]. Out of the 11 genes identified in zebrafish that relate to PKD, 6 were found to be ciliary genes [142]. These mutants and more, show the importance of cilia and pathways in regulating renal cells.

Although CT and MRI techniques can be used, diagnosis by ultrasound and positive family history are the choice methods to test for PKD [143]. ARPKD can even be detected in utero by ultrasound which reveals large kidneys that take up most of the fetal abdominal cavity 
and the lack of urine in the bladder [130]. Nuclear magnetic resonance (NMR) spectroscopy also allows discrimination between PKD and other kidney diseases with an accuracy of over $80 \%$, by creating a fingerprint of urinary protein biomarkers with key PKD features [143]. Since most PKD patients have mutations in known PKD genes, genetic testing may be plausible. However, since there are hundreds of possible mutations, the only commonly used genetics testing is direct sequencing to screen for the disease [144].

There is currently no effective treatment that is widely used for PKD. Transplantation and dialysis are often the only options. Apart from that, pain control, antibiotics for urinary tract infections, increase in fluid intake, and refraining from smoking and caffeine, are ways of lessening the symptoms [130]. However, many potential drugs for treating cystogenesis are under investigation. Many drugs have shown to slow cyst growth in animal models. Rapamycin helps regulate cell proliferation by inhibiting the mTOR pathway, which is often overexpressed in PKD patients. This drug increases apoptosis and shedding of cystic cells, which decreases kidney size and restored kidney function [145]. Roscovitine, currently used in cancer treatment because it inhibits cell cycle, show positive effects in PKD models [146]. Lisinopril, an inhibitor of angiotensin converting enzyme (ACE) also alters proliferative and apoptotic pathways, reducing cyst development [147]. Patients with PKD show high levels of circulating vasopressin. Tolvaptin is a vasopressin- 2 receptor antagonist and shows reduction in kidney and cyst volumes [148]. Ocreatide, an analogue of the hormone somatostatin, inhibits cAMP production. In doing so, it inhibits secretion and reduces liver cysts and kidney volume. However, it does not seem to improve renal function [149, 150]. Epidermal growth factor receptor (EGFR) tyrosine kinase inhibition using EKI-785 also showed promise in PKD animal studies [151]. Anti-inflammatory drug, colchicine, is a microtubule inhibitor that has been shown to delay formation of cysts and is a candidate for prolonged clinical use [152].

PKD mutants are giving us a better understanding of the importance of cilia in many regulatory pathways and sensory functions. The disease further emphasizes how complex these seemingly simple cellular organelles are, and how necessary they are in maintaining systemic health and prevention of cystic growth.

\subsection{Bardet-Biedl Syndrome (BBS)}

Many syndromes are related to cilia, Bardet-Biedl syndrome being the most well-known. Bardet-Biedl Syndrome (BBS) is a multi-symptomatic disorder with symptoms including obesity, retinitis pigmentosa, genital hypoplasia, polydactyly, and mental retardation [153]. Typically at age 8, night blindness occurs which can eventually lead to complete blindness between ages 15 and 20 . Kidney cysts are also common, making end-stage renal failure the most common cause of premature death in BBS patients [154]. Mid-facial deformities are often seen in humans with BBS and also in mice mutants for BBS4 and BBS6 [131]. Although this is a very multi-symptomatic disorder, obesity is what it is most known for. Ninetyeight percent of BBS patients become obese with a body mass index greater than $30 \%$ [155]. Diabetes occurs secondary to obesity, and patients often show lower locomotor activity than normal [156, 157].

Phototransduction proteins and others necessary for vision are produced in the inner segment of photoreceptor cells. To maintain the outer segments, the phototransduction 
proteins have to be transported to the outer segments of the photoreceptors through the connecting cilia, the only bridge between outer and inner segments. BBS proteins form a BBSome and are believed to be responsible for recruiting membrane vesicles to the cilia [16, 47]. BBS proteins are also involved in important pathways such as Wnt and Hedgehog pathways which are very important for proper development and function [153]. Hedgehog and Wnt signaling are anti-adipogenic, preventing obesity [158-160]. It is now believed that obesity in BBS patients is linked to the impairment of ciliated cells in the hypothalamus to sense satiety, inducing hyperphagia [161]. BBS proteins may be important in transport of leptin in and out of the cells, causing loss of leptin signaling ability when cilia are lost. Moreover, melanin concentrating hormone receptor-1 (Mchr1) is involved in regulation of feeding behavior, and fails to localize to cilia in BBS mutants [161,162]. These are just a few of the possible factors that may be involved in causing obesity in BBS patients.

BBS is an autosomal recessive disease showing pleiotropy, with multiple traits being affected. Development of the disorder often requires more than three mutations in at least 2 BBS genes [163]. Apart from the causative mutations, other BBS mutations often serve as disease modifiers. So far there are 12 known BBS genes, BBS1-12, which code for proteins important in trafficking cargo to the basal body and along the cilia. Other ciliary proteins have also been linked to BBS [154]. Among these are Kif3A and Tg737 mutants, which show hyperphagic activity and obesity, in addition to elevated plasma levels of glucose, insulin, and leptin [164].

Diagnosis of BBS typically requires the presence of at least four primary symptoms or three primary in addition to two secondary symptoms. Primary symptoms include cone-rod dystrophy, polydactyly, obesity, learning disability, genital defects, and renal anomalies. Secondary symptoms include speech impairment, brachydactyly (short digits), syndachtyly (fused digits), developmental delay, polyuria (excessive urination), ploydypsia (excessive thirst), ataxia (lack of muscle coordination), diabetes, heart and liver problems, olfactory deficits, and defects in pain and temperature sensation [154].

Since BBS is syndromic and affects multiple systems, treatment can be multi-faceted. Gene therapy has shown promise in treating vision impairments. Mice, in which Bbs4 has been deleted, show an inability of rhodopsin to localize to rod cilia and cone opsins to localize to cone cilia. This failure to localize leads to photoreceptor apoptosis and the deterioration of electroretinogram (ERG) a- and b-waves, causing serious vision impairment. Recently, adeno-associated viral (AAV) vectors have shown to be successful in incorporating Bbs4 into these mutants and restoring the localization of rhodopsin. In doing so, photoreceptor death was prevented, function of the retina was restored, and mice showed recovery of visual behavioral responses [165]. Surgical techniques are used for other symptoms of BBS. For instance renal transplantation is used in the case of cystic kidneys. Obesity is important to treat, since it has been shown to cause a fifty percent increase in mortality rates most likely caused by complications from secondary diseases. These include diabetes, cardiovascular diseases, cerebrovascular diseases, digestive disorders, gall bladder cancer, breast cancer, endometrium cancer, prostate cancer, etc [166, 167]. Bariatric surgeries such as gastric bypass and gastric band operations greatly improve weight loss in patients with obesity. These operations also show a dramatic improvement in reducing the risk of secondary diseases that are known to be associated with obesity. Because of the reduction in the incidence of these diseases, the mortality rate decreases substantially [168]. In 
addition to surgical procedures, drug treatments have also been under review for the treatment of obesity. There are only two drugs currently accepted by the U.S. Food and Drug Administration for long term obesity treatment. This is due to the high prevalence of severe side effects correlated with the use of weight loss drugs. These side effects include heart attack, gastrointestinal distress, liver damage, anxiety, memory problems, suicide, and are often habit-forming. Because of these serious issues, it is important to be skeptical in determining which drugs are safe to be used to treat obesity [169]. These are only a few of the current treatments being used for BBS-related symptoms, and many others are yet to be discovered.

Again, BBS adds further support to the idea that cilia are important in many areas throughout the body, and they are very important in maintaining the overall health of the individual.

\subsection{Cancer}

Relating cancer to cilia is one of the newest areas of ciliary research in the field today. The cilia assembly-disassembly cycle is closely linked with the cell cycle. Cilia assemble upon exit of mitosis to the stationary phase, and resorb when the cell exits the S-phase and enters mitosis [170]. When the ciliogenesis is disrupted, it may have adverse effects on cell cycle and lead to cancer. This may be due to centrosomal amplification and genetic instability [171]. Proteins necessary for ciliogenesis colocalize to the centrosome, also supporting the link between cilia and cell cycle [172]. Cilia have also been found to play roles in important pathways such as Sonic Hedgehog, signal transduction pathways, and ligand-induced signaling. These pathways have recently been shown to relate to cancer. New insights are being made to connect ciliary dysfunction to carcinogenesis [172].

Primary cilia appear to have dual opposing functions in development of different types of cancer, so that some refer to them as being an On/Off switch, regulating tumorigenesis [173, 174]. One of the most important pathways related to ciliogenesis and cancer is the Hedgehog $(\mathrm{Hh})$ pathway. Hh is normally suppressed by Ptch1 which prevents the trafficking of Smo in primary cilia. When Smo fails to localize to cilia, it prevents Hh signaling. Under cancerous conditions, however, Smo is able to localize to the cilia and Hh signaling is overexpressed leading to oncogenesis [175]. SmoM2 leads to brain tumors only if primary cilia are present. However, Gli $2 \Delta \mathrm{N}$ induces brain tumors only in the absence of cilia, since absence of cilia causes a disruption in Gli3, a repressor of Gli2 $\Delta \mathrm{N}[174,176]$. It appears that primary cilia are required both for the suppression and expression of oncogenisis. Primary cilia suppress oncogenic mutations that act downstream of cilia, but allow expression of oncogenic mutations upstream of cilia $[173,174,177]$. Therefore, cilia can play opposite roles depending on the causal mutation of the cancer development $[173,174]$.

Disruptions in Hh, Wnt, and PDGF pathways all have been linked to tumor formation. Cilia-associated genes such as Gli1, RPGRIP1, and DNAH9 are often mutated in breast cancer [177]. Nek8 is also localized to cilia and upregulated in breast cancer [178, 179]. Pancreatic ductal adenocarcinoma (PDAC) is the fourth leading cause of cancer deaths in the United States [180]. In this case, excessive Hh signaling is caused by a mutation in a Kras gene[181], which codes for a protein known to be important in ciliogenesis. Therefore affected cells lack primary cilia, and are unable to regulate proliferation [182]. 
German pathologist, Rudolf Virchow, first defined cancer in the mid-1800s when he realized that Leukemia was caused by a rapid duplication of healthy cells that had mutated and in response, multiplied. Before the advent of modern-day technology, cancer was not diagnosed or treated until the tumors became visible and palpable, in which case they were surgically removed. Since then, however, an emphasis has been placed on early detection so that doctors can treat the cancer before it turns into large fatal tumors. Most doctors recommend certain regular screening for some types of cancer. Among these are mammograms for breast cancer, colonoscopies for colon cancer, Pap smears for cervical cancer, and prostate exams for prostate cancer. Other diagnostic tests include blood tests, ultrasounds, computed tomography (CT), X-ray, magnetic resonance imaging (MRI), and fine-needle biopsies. These techniques are used to detect early signs of cancer, allowing an earlier treatment and an attempt to prevent fatality [183].

Cancer treatment is one of the most prioritized areas of research today. Many treatments are currently being used and even more are being tested. These treatments include chemotherapy, radiation therapy, surgery, and gene therapy. Perhaps the implications in the relationship with cilia and cell cycle will help lead to the development of new treatments.

Primary ciliary dyskinesia, hydrocephalus, polycystic kidney disease, Bardet-Biedl syndrome, and cancer are only a few of the known ciliopathies, and more are still being discovered. These diseases are not only important to study for diagnostic and treatment purposes, but also give us a clearer understanding about cilia and their role in most critical bodily functions. Further ciliopathy studies will continue to shed new light on these important cellular structures.

The research in the Qin lab is supported by the NSF grant MCB-0923835.

\section{References}

[1] H. Ishikawa and W. F. Marshall, "Ciliogenesis: building the cell's antenna," Nat Rev Mol Cell Biol, vol. 12, pp. 222-34, Apr 2011.

[2] G. J. Pazour and G. B. Witman, "The vertebrate primary cilium is a sensory organelle," Curr Opin Cell Biol, vol. 15, pp. 105-10, Feb 2003.

[3] K. G. Kozminski, K. A. Johnson, P. Forscher, and J. L. Rosenbaum, "A motility in the eukaryotic flagellum unrelated to flagellar beating," Proc Natl Acad Sci U S A, vol. 90, pp. 5519-23, Jun 151993.

[4] J. Rosenbaum, "Intraflagellar transport," Curr Biol, vol. 12, p. R125, Feb 192002.

[5] D. G. Cole, D. R. Diener, A. L. Himelblau, P. L. Beech, J. C. Fuster, and J. L. Rosenbaum, "Chlamydomonas kinesin-II-dependent intraflagellar transport (IFT): IFT particles contain proteins required for ciliary assembly in Caenorhabditis elegans sensory neurons," J Cell Biol, vol. 141, pp. 993-1008, May 181998.

[6] K. G. Kozminski, P. L. Beech, and J. L. Rosenbaum, "The Chlamydomonas kinesin-like protein FLA10 is involved in motility associated with the flagellar membrane," J Cell Biol, vol. 131, pp. 1517-27, Dec 1995.

[7] G. J. Pazour, C. G. Wilkerson, and G. B. Witman, "A dynein light chain is essential for the retrograde particle movement of intraflagellar transport (IFT)," J Cell Biol, vol. 141, pp. 979-92, May 181998. 
[8] G. J. Pazour, B. L. Dickert, and G. B. Witman, "The DHC1b (DHC2) isoform of cytoplasmic dynein is required for flagellar assembly," J Cell Biol, vol. 144, pp. 47381, Feb 81999.

[9] P. Rompolas, L. B. Pedersen, R. S. Patel-King, and S. M. King, "Chlamydomonas FAP133 is a dynein intermediate chain associated with the retrograde intraflagellar transport motor," J Cell Sci, vol. 120, pp. 3653-65, Oct 152007.

[10] D. J. Asai, V. Rajagopalan, and D. E. Wilkes, "Dynein-2 and ciliogenesis in Tetrahymena," Cell Motil Cytoskeleton, vol. 66, pp. 673-7, Aug 2009.

[11] L. Hao, E. Efimenko, P. Swoboda, and J. M. Scholey, "The Retrograde IFT Machinery of C. elegans Cilia: Two IFT Dynein Complexes?," PLoS One, vol. 6, p. e20995, 2011.

[12] J. M. Scholey, "Intraflagellar transport motors in cilia: moving along the cell's antenna," J Cell Biol, vol. 180, pp. 23-9, Jan 142008.

[13] J. M. Scholey, "Intraflagellar transport," Annu Rev Cell Dev Biol, vol. 19, pp. 423-43, 2003.

[14] M. E. Porter, R. Bower, J. A. Knott, P. Byrd, and W. Dentler, "Cytoplasmic dynein heavy chain $1 \mathrm{~b}$ is required for flagellar assembly in Chlamydomonas," Mol Biol Cell, vol. 10, pp. 693-712, Mar 1999.

[15] W. F. Marshall and J. L. Rosenbaum, "Intraflagellar transport balances continuous turnover of outer doublet microtubules: implications for flagellar length control," $J$ Cell Biol, vol. 155, pp. 405-14, Oct 292001.

[16] M. V. Nachury, E. S. Seeley, and H. Jin, "Trafficking to the ciliary membrane: how to get across the periciliary diffusion barrier?," Annu Rev Cell Dev Biol, vol. 26, pp. 59-87, Nov 102010.

[17] K. F. Lechtreck, E. C. Johnson, T. Sakai, D. Cochran, B. A. Ballif, J. Rush, G. J. Pazour, M. Ikebe, and G. B. Witman, "The Chlamydomonas reinhardtii BBSome is an IFT cargo required for export of specific signaling proteins from flagella," J Cell Biol, vol. 187, pp. 1117-32, Dec 282009.

[18] D. G. Cole, S. W. Chinn, K. P. Wedaman, K. Hall, T. Vuong, and J. M. Scholey, "Novel heterotrimeric kinesin-related protein purified from sea urchin eggs," Nature, vol. 366, pp. 268-70, Nov 181993.

[19] D. G. Cole, "The intraflagellar transport machinery of Chlamydomonas reinhardtii," Traffic, vol. 4, pp. 435-42, Jul 2003.

[20] K. Matsuura, P. A. Lefebvre, R. Kamiya, and M. Hirono, "Kinesin-II is not essential for mitosis and cell growth in Chlamydomonas," Cell Motil Cytoskeleton, vol. 52, pp. 195-201, Aug 2002.

[21] J. J. Snow, G. Ou, A. L. Gunnarson, M. R. Walker, H. M. Zhou, I. Brust-Mascher, and J. M. Scholey, "Two anterograde intraflagellar transport motors cooperate to build sensory cilia on C. elegans neurons," Nat Cell Biol, vol. 6, pp. 1109-13, Nov 2004.

[22] N. S. Morsci and M. M. Barr, "Kinesin-3 KLP-6 Regulates Intraflagellar Transport in Male-Specific Cilia of Caenorhabditis elegans," Curr Biol, vol. 21, pp. 1239-44, Jul 26 2011.

[23] Y. Hou, G. J. Pazour, and G. B. Witman, "A dynein light intermediate chain, D1bLIC, is required for retrograde intraflagellar transport," Mol Biol Cell, vol. 15, pp. 4382-94, Oct 2004.

[24] C. A. Perrone, D. Tritschler, P. Taulman, R. Bower, B. K. Yoder, and M. E. Porter, "A novel dynein light intermediate chain colocalizes with the retrograde motor for 
intraflagellar transport at sites of axoneme assembly in chlamydomonas and Mammalian cells," Mol Biol Cell, vol. 14, pp. 2041-56, May 2003.

[25] J. C. Schafer, C. J. Haycraft, J. H. Thomas, B. K. Yoder, and P. Swoboda, "XBX-1 encodes a dynein light intermediate chain required for retrograde intraflagellar transport and cilia assembly in Caenorhabditis elegans," Mol Biol Cell, vol. 14, pp. 2057-70, May 2003.

[26] D. Signor, K. P. Wedaman, J. T. Orozco, N. D. Dwyer, C. I. Bargmann, L. S. Rose, and J. M. Scholey, "Role of a class DHC1b dynein in retrograde transport of IFT motors and IFT raft particles along cilia, but not dendrites, in chemosensory neurons of living Caenorhabditis elegans," J Cell Biol, vol. 147, pp. 519-30, Nov 11999.

[27] L. B. Pedersen and J. L. Rosenbaum, "Intraflagellar transport (IFT) role in ciliary assembly, resorption and signalling," Curr Top Dev Biol, vol. 85, pp. 23-61, 2008.

[28] S. M. Williamson, D. A. Silva, E. Richey, and H. Qin, "Probing the role of IFT particle complex A and B in flagellar entry and exit of IFT-dynein in Chlamydomonas" Protoplasma, 2011.

[29] G. Piperno, E. Siuda, S. Henderson, M. Segil, H. Vaananen, and M. Sassaroli, "Distinct mutants of retrograde intraflagellar transport (IFT) share similar morphological and molecular defects," J Cell Biol, vol. 143, pp. 1591-601, Dec 141998.

[30] C. Iomini, L. Li, J. M. Esparza, and S. K. Dutcher, "Retrograde intraflagellar transport mutants identify complex A proteins with multiple genetic interactions in Chlamydomonas reinhardtii," Genetics, vol. 183, pp. 885-96, Nov 2009.

[31] J. Mueller, C. A. Perrone, R. Bower, D. G. Cole, and M. E. Porter, "The FLA3 KAP subunit is required for localization of kinesin- 2 to the site of flagellar assembly and processive anterograde intraflagellar transport," Mol Biol Cell, vol. 16, pp. 1341-54, Mar 2005.

[32] C. Li, P. N. Inglis, C. C. Leitch, E. Efimenko, N. A. Zaghloul, C. A. Mok, E. E. Davis, N. J. Bialas, M. P. Healey, E. Heon, M. Zhen, P. Swoboda, N. Katsanis, and M. R. Leroux, "An essential role for DYF-11/MIP-T3 in assembling functional intraflagellar transport complexes," PLoS Genet, vol. 4, p. e1000044, Mar 2008.

[33] J. F. Dishinger, H. L. Kee, P. M. Jenkins, S. Fan, T. W. Hurd, J. W. Hammond, Y. N. Truong, B. Margolis, J. R. Martens, and K. J. Verhey, "Ciliary entry of the kinesin-2 motor KIF17 is regulated by importin-beta2 and RanGTP," Nat Cell Biol, vol. 12, pp. 703-10, Jul 2010.

[34] B. F. Lucker, R. H. Behal, H. Qin, L. C. Siron, W. D. Taggart, J. L. Rosenbaum, and D. G. Cole, "Characterization of the intraflagellar transport complex B core: direct interaction of the IFT81 and IFT74/72 subunits," J Biol Chem, vol. 280, pp. 27688-96, Jul 292005.

[35] B. F. Lucker, M. S. Miller, S. A. Dziedzic, P. T. Blackmarr, and D. G. Cole, "Direct interactions of intraflagellar transport complex B proteins IFT88, IFT52 and IFT46," J Biol Chem, vol. 2010, Apr 302010.

[36] M. Taschner, S. Bhogaraju, M. Vetter, M. Morawetz, and E. Lorentzen, "Biochemical Mapping of Interactions within the Intraflagellar Transport (IFT) B Core Complex: IFT52 BINDS DIRECTLY TO FOUR OTHER IFT-B SUBUNITS," J Biol Chem, vol. 286, pp. 26344-52, Jul 292011.

[37] G. J. Pazour, B. L. Dickert, Y. Vucica, E. S. Seeley, J. L. Rosenbaum, G. B. Witman, and D. G. Cole, "Chlamydomonas IFT88 and its mouse homologue, polycystic kidney 
disease gene tg737, are required for assembly of cilia and flagella," J Cell Biol, vol. 151, pp. 709-18, Oct 302000.

[38] Y. Hou, H. Qin, J. A. Follit, G. J. Pazour, J. L. Rosenbaum, and G. B. Witman, "Functional analysis of an individual IFT protein: IFT46 is required for transport of outer dynein arms into flagella," J Cell Biol, vol. 176, pp. 653-65, Feb 262007.

[39] N. T. Ahmed, C. Gao, B. F. Lucker, D. G. Cole, and D. R. Mitchell, "ODA16 aids axonemal outer row dynein assembly through an interaction with the intraflagellar transport machinery," J Cell Biol, vol. 183, pp. 313-22, Oct 202008.

[40] J. A. Follit, R. A. Tuft, K. E. Fogarty, and G. J. Pazour, "The intraflagellar transport protein IFT20 is associated with the Golgi complex and is required for cilia assembly," Mol Biol Cell, vol. 17, pp. 3781-92, Sep 2006.

[41] B. L. Krock and B. D. Perkins, "The intraflagellar transport protein IFT57 is required for cilia maintenance and regulates IFT-particle-kinesin-II dissociation in vertebrate photoreceptors," J Cell Sci, vol. 121, pp. 1907-15, Jun 12008.

[42] L. B. Pedersen, M. S. Miller, S. Geimer, J. M. Leitch, J. L. Rosenbaum, and D. G. Cole, "Chlamydomonas IFT172 is encoded by FLA11, interacts with CrEB1, and regulates IFT at the flagellar tip," Curr Biol, vol. 15, pp. 262-6, Feb 82005.

[43] L. B. Pedersen, S. Geimer, and J. L. Rosenbaum, "Dissecting the molecular mechanisms of intraflagellar transport in chlamydomonas," Curr Biol, vol. 16, pp. 450-9, Mar 7 2006.

[44] J. Qin, Y. Lin, R. X. Norman, H. W. Ko, and J. T. Eggenschwiler, "Intraflagellar transport protein 122 antagonizes Sonic Hedgehog signaling and controls ciliary localization of pathway components," Proc Natl Acad Sci U S A, vol. 108, pp. 1456-61, Jan 25 2011.

[45] E. Lee, E. Sivan-Loukianova, D. F. Eberl, and M. J. Kernan, "An IFT-A protein is required to delimit functionally distinct zones in mechanosensory cilia," Curr Biol, vol. 18, pp. 1899-906, Dec 232008.

[46] G. Ou, O. E. Blacque, J. J. Snow, M. R. Leroux, and J. M. Scholey, "Functional coordination of intraflagellar transport motors," Nature, vol. 436, pp. 583-7, Jul 28 2005.

[47] M. V. Nachury, A. V. Loktev, Q. Zhang, C. J. Westlake, J. Peranen, A. Merdes, D. C. Slusarski, R. H. Scheller, J. F. Bazan, V. C. Sheffield, and P. K. Jackson, "A core complex of BBS proteins cooperates with the GTPase Rab8 to promote ciliary membrane biogenesis," Cell, vol. 129, pp. 1201-13, Jun 152007.

[48] H. Jin, S. R. White, T. Shida, S. Schulz, M. Aguiar, S. P. Gygi, J. F. Bazan, and M. V. Nachury, "The conserved Bardet-Biedl syndrome proteins assemble a coat that traffics membrane proteins to cilia," Cell, vol. 141, pp. 1208-19, Jun 252010.

[49] S. Cevik, Y. Hori, O. I. Kaplan, K. Kida, T. Toivenon, C. Foley-Fisher, D. Cottell, T. Katada, K. Kontani, and O. E. Blacque, "Joubert syndrome Arl13b functions at ciliary membranes and stabilizes protein transport in Caenorhabditis elegans," J Cell Biol, vol. 188, pp. 953-69, Mar 222010.

[50] Y. Li, Q. Wei, Y. Zhang, K. Ling, and J. Hu, "The small GTPases ARL-13 and ARL-3 coordinate intraflagellar transport and ciliogenesis," J Cell Biol, vol. 189, pp. 1039-51, Jun 142010. 
[51] N. A. Duldulao, S. Lee, and Z. Sun, "Cilia localization is essential for in vivo functions of the Joubert syndrome protein Arl13b/Scorpion," Development, vol. 136, pp. 4033-42, Dec 2009.

[52] C. J. Westlake, L. M. Baye, M. V. Nachury, K. J. Wright, K. E. Ervin, L. Phu, C. Chalouni, J. S. Beck, D. S. Kirkpatrick, D. C. Slusarski, V. C. Sheffield, R. H. Scheller, and P. K. Jackson, "Primary cilia membrane assembly is initiated by Rab11 and transport protein particle II (TRAPPII) complex-dependent trafficking of Rabin8 to the centrosome," Proc Natl Acad Sci U S A, vol. 108, pp. 2759-64, Feb 152011.

[53] A. Knodler, S. Feng, J. Zhang, X. Zhang, A. Das, J. Peranen, and W. Guo, "Coordination of Rab8 and Rab11 in primary ciliogenesis," Proc Natl Acad Sci U S A, vol. 107, pp. 6346-51, Apr 62010.

[54] J. Mazelova, L. Astuto-Gribble, H. Inoue, B. M. Tam, E. Schonteich, R. Prekeris, O. L. Moritz, P. A. Randazzo, and D. Deretic, "Ciliary targeting motif VxPx directs assembly of a trafficking module through Arf4," Embo J, vol. 28, pp. 183-92, Feb 4 2009.

[55] H. H. Ward, U. Brown-Glaberman, J. Wang, Y. Morita, S. L. Alper, E. J. Bedrick, V. H. Gattone, 2nd, D. Deretic, and A. Wandinger-Ness, "A conserved signal and GTPase complex are required for the ciliary transport of polycystin-1," Mol Biol Cell, vol. 2011, Jul 202011.

[56] C. Boehlke, M. Bashkurov, A. Buescher, T. Krick, A. K. John, R. Nitschke, G. Walz, and E. W. Kuehn, "Differential role of Rab proteins in ciliary trafficking: Rab23 regulates smoothened levels," J Cell Sci, vol. 123, pp. 1460-7, May 12010.

[57] Z. Wang, Z. C. Fan, S. M. Williamson, and H. Qin, "Intraflagellar transport (IFT) protein IFT25 is a phosphoprotein component of IFT complex B and physically interacts with IFT27 in Chlamydomonas," PLoS One, vol. 4, p. e5384, 2009.

[58] S. Bhogaraju, M. Taschner, M. Morawetz, C. Basquin, and E. Lorentzen, "Crystal structure of the intraflagellar transport complex 25/27," Embo J, Apr 192011.

[59] J. C. Schafer, M. E. Winkelbauer, C. L. Williams, C. J. Haycraft, R. A. Desmond, and B. K. Yoder, "IFTA-2 is a conserved cilia protein involved in pathways regulating longevity and dauer formation in Caenorhabditis elegans," J Cell Sci, vol. 119, pp. 4088-100, Oct 12006.

[60] C. Adhiambo, T. Blisnick, G. Toutirais, E. Delannoy, and P. Bastin, "A novel function for the atypical small $G$ protein Rab-like 5 in the assembly of the trypanosome flagellum," J Cell Sci, vol. 122, pp. 834-41, Mar 152009.

[61] J. L. Rosenbaum and G. B. Witman, "Intraflagellar transport," Nat Rev Mol Cell Biol, vol. 3, pp. 813-25, Nov 2002.

[62] B. Craige, C. C. Tsao, D. R. Diener, Y. Hou, K. F. Lechtreck, J. L. Rosenbaum, and G. B. Witman, "CEP290 tethers flagellar transition zone microtubules to the membrane and regulates flagellar protein content," J Cell Biol, vol. 190, pp. 927-40, Sep 62010.

[63] H. Omran, "NPHP proteins: gatekeepers of the ciliary compartment," J Cell Biol, vol. 190, pp. 715-7, Sep 62010.

[64] C. L. Williams, C. Li, K. Kida, P. N. Inglis, S. Mohan, L. Semenec, N. J. Bialas, R. M. Stupay, N. Chen, O. E. Blacque, B. K. Yoder, and M. R. Leroux, "MKS and NPHP modules cooperate to establish basal body/transition zone membrane associations and ciliary gate function during ciliogenesis," J Cell Biol, vol. 192, pp. 1023-41, Mar 212011. 
[65] S. S. Francis, J. Sfakianos, B. Lo, and I. Mellman, "A hierarchy of signals regulates entry of membrane proteins into the ciliary membrane domain in epithelial cells," J Cell Biol, vol. 193, pp. 219-33, Apr 42011.

[66] T. Takeda, T. McQuistan, R. A. Orlando, and M. G. Farquhar, "Loss of glomerular foot processes is associated with uncoupling of podocalyxin from the actin cytoskeleton," J Clin Invest, vol. 108, pp. 289-301, Jul 2001.

[67] J. Gaertig and D. Wloga, "Ciliary tubulin and its post-translational modifications," Curr Top Dev Biol, vol. 85, pp. 83-113, 2008.

[68] D. Wloga and J. Gaertig, "Post-translational modifications of microtubules," J Cell Sci, vol. 123, pp. 3447-55, Oct 152010.

[69] K. Greer, H. Maruta, S. W. L'Hernault, and J. L. Rosenbaum, "Alpha-tubulin acetylase activity in isolated Chlamydomonas flagella," J Cell Biol, vol. 101, pp. 2081-4, Dec 1985.

[70] S. W. L'Hernault and J. L. Rosenbaum, "Reversal of the posttranslational modification on Chlamydomonas flagellar alpha-tubulin occurs during flagellar resorption," J Cell Biol, vol. 100, pp. 457-62, Feb 1985.

[71] S. W. L'Hernault and J. L. Rosenbaum, "Chlamydomonas alpha-tubulin is posttranslationally modified by acetylation on the epsilon-amino group of a lysine," Biochemistry, vol. 24, pp. 473-8, Jan 151985.

[72] C. Choudhary, C. Kumar, F. Gnad, M. L. Nielsen, M. Rehman, T. C. Walther, J. V. Olsen, and M. Mann, "Lysine acetylation targets protein complexes and co-regulates major cellular functions," Science, vol. 325, pp. 834-40, Aug 142009.

[73] J. S. Akella, D. Wloga, J. Kim, N. G. Starostina, S. Lyons-Abbott, N. S. Morrissette, S. T. Dougan, E. T. Kipreos, and J. Gaertig, "MEC-17 is an alpha-tubulin acetyltransferase," Nature, vol. 467, pp. 218-22, Sep 92010.

[74] T. Shida, J. G. Cueva, Z. Xu, M. B. Goodman, and M. V. Nachury, "The major alphatubulin K40 acetyltransferase alphaTAT1 promotes rapid ciliogenesis and efficient mechanosensation," Proc Natl Acad Sci U S A, vol. 107, pp. 21517-22, Dec 142010.

[75] K. Huang, D. R. Diener, and J. L. Rosenbaum, "The ubiquitin conjugation system is involved in the disassembly of cilia and flagella," J Cell Biol, vol. 186, pp. 601-13, Aug 242009.

[76] A. V. Loktev, Q. Zhang, J. S. Beck, C. C. Searby, T. E. Scheetz, J. F. Bazan, D. C. Slusarski, V. C. Sheffield, P. K. Jackson, and M. V. Nachury, "A BBSome subunit links ciliogenesis, microtubule stability, and acetylation," Dev Cell, vol. 15, pp. 85465, Dec 2008.

[77] J. C. Bulinski, "Tubulin posttranslational modifications: a Pushmi-Pullyu at work?," Dev Cell, vol. 16, pp. 773-4, Jun 2009.

[78] K. Rogowski, F. Juge, J. van Dijk, D. Wloga, J. M. Strub, N. Levilliers, D. Thomas, M. H. Bre, A. Van Dorsselaer, J. Gaertig, and C. Janke, "Evolutionary divergence of enzymatic mechanisms for posttranslational polyglycylation," Cell, vol. 137, pp. 1076-87, Jun 122009.

[79] D. Wloga, D. M. Webster, K. Rogowski, M. H. Bre, N. Levilliers, M. Jerka-Dziadosz, C. Janke, S. T. Dougan, and J. Gaertig, "TTLL3 Is a tubulin glycine ligase that regulates the assembly of cilia," Dev Cell, vol. 16, pp. 867-76, Jun 2009.

[80] S. Suryavanshi, B. Edde, L. A. Fox, S. Guerrero, R. Hard, T. Hennessey, A. Kabi, D. Malison, D. Pennock, W. S. Sale, D. Wloga, and J. Gaertig, "Tubulin glutamylation 
regulates ciliary motility by altering inner dynein arm activity," Curr Biol, vol. 20, pp. 435-40, Mar 92010.

[81] T. Kubo, H. A. Yanagisawa, T. Yagi, M. Hirono, and R. Kamiya, "Tubulin polyglutamylation regulates axonemal motility by modulating activities of innerarm dyneins," Curr Biol, vol. 20, pp. 441-5, Mar 92010.

[82] F. Hildebrandt, T. Benzing, and N. Katsanis, "Ciliopathies," N Engl J Med, vol. 364, pp. 1533-43, Apr 212011.

[83] B. A. Afzelius, "A human syndrome caused by immotile cilia," Science, vol. 193, pp. 3179, Jul 231976.

[84] M. A. Zariwala, M. R. Knowles, and M. W. Leigh, "Primary Ciliary Dyskinesia," 1993.

[85] M. Meeks, A. Walne, S. Spiden, H. Simpson, H. Mussaffi-Georgy, H. D. Hamam, E. L. Fehaid, M. Cheehab, M. Al-Dabbagh, S. Polak-Charcon, H. Blau, A. O'Rawe, H. M. Mitchison, R. M. Gardiner, and E. Chung, "A locus for primary ciliary dyskinesia maps to chromosome 19q," J Med Genet, vol. 37, pp. 241-4, Apr 2000.

[86] M. Meeks and A. Bush, "Primary ciliary dyskinesia (PCD)," Pediatr Pulmonol, vol. 29, pp. 307-16, Apr 2000.

[87] A. Bush and C. O'Callaghan, "Primary ciliary dyskinesia," Arch Dis Child, vol. 87, pp. 363-5; discussion 363-5, Nov 2002.

[88] A. Wanner, M. Salathe, and T. G. O'Riordan, "Mucociliary clearance in the airways," Am J Respir Crit Care Med, vol. 154, pp. 1868-902, Dec 1996.

[89] S. Nonaka, H. Shiratori, Y. Saijoh, and H. Hamada, "Determination of left-right patterning of the mouse embryo by artificial nodal flow," Nature, vol. 418, pp. 96-9, Jul 42002.

[90] D. M. Supp, D. P. Witte, S. S. Potter, and M. Brueckner, "Mutation of an axonemal dynein affects left-right asymmetry in inversus viscerum mice," Nature, vol. 389, pp. 963-6, Oct 301997.

[91] J. Chen, H. J. Knowles, J. L. Hebert, and B. P. Hackett, "Mutation of the mouse hepatocyte nuclear factor/forkhead homologue 4 gene results in an absence of cilia and random left-right asymmetry," J Clin Invest, vol. 102, pp. 1077-82, Sep 151998.

[92] S. Nonaka, Y. Tanaka, Y. Okada, S. Takeda, A. Harada, Y. Kanai, M. Kido, and N. Hirokawa, "Randomization of left-right asymmetry due to loss of nodal cilia generating leftward flow of extraembryonic fluid in mice lacking KIF3B motor protein," Cell, vol. 95, pp. 829-37, Dec 111998.

[93] B. A. Afzelius, B. Mossberg, and S. E. Bergstrom, "Immotile cilia syndrome (primary ciliary dyskinesia), including Kartagener syndrome. ," in The metabolic and molecular bases of inherited disease. , C. R. Scriver, A. L. Beaudet, W. S. Sly, and D. Valle, Eds. New York: McGraw-Hill Medical Publishing Division, 2001, pp. 4817-4827.

[94] P. J. Hadfield, J. M. Rowe-Jones, A. Bush, and I. S. Mackay, "Treatment of otitis media with effusion in children with primary ciliary dyskinesia," Clin Otolaryngol Allied Sci, vol. 22, pp. 302-6, Aug 1997.

[95] A. Gurr, T. Stark, M. Pearson, G. Borkowski, and S. Dazert, "The ciliary beat frequency of middle ear mucosa in children with chronic secretory otitis media," Eur Arch Otorhinolaryngol, vol. 266, pp. 1865-70, Dec 2009.

[96] L. E. Ostrowski, W. Yin, K. E. Thonmpson, M. Patel, and J. C. Olsen, "Pilot studies of gene therapy for primary ciliary dyskinesia," Am J Respir Crit Care Med, 2010. 
[97] N. Hornef, H. Olbrich, J. Horvath, M. A. Zariwala, M. Fliegauf, N. T. Loges, J. Wildhaber, P. G. Noone, M. Kennedy, S. E. Antonarakis, J. L. Blouin, L. Bartoloni, T. Nusslein, P. Ahrens, M. Griese, H. Kuhl, R. Sudbrak, M. R. Knowles, R. Reinhardt, and H. Omran, "DNAH5 mutations are a common cause of primary ciliary dyskinesia with outer dynein arm defects," Am J Respir Crit Care Med, vol. 174, pp. 120-6, Jul 152006.

[98] G. Pennarun, E. Escudier, C. Chapelin, A. M. Bridoux, V. Cacheux, G. Roger, A. Clement, M. Goossens, S. Amselem, and B. Duriez, "Loss-of-function mutations in a human gene related to Chlamydomonas reinhardtii dynein IC78 result in primary ciliary dyskinesia," Am J Hum Genet, vol. 65, pp. 1508-19, Dec 1999.

[99] W. Stannard, A. Rutman, C. Wallis, and C. O'Callaghan, "Central microtubular agenesis causing primary ciliary dyskinesia," Am J Respir Crit Care Med, vol. 169, pp. 634-7, Mar 12004.

[100] G. B. Harris, J. C. R. Bermejo, and M. C. Suarez, "Different frequency of cilia with transposition in human nasal and bronchial mucosa. A case of acquired ciliary dyskinesia," Virchows Archiv-an International Journal of Pathology, vol. 437, pp. 325330, Sep 2000.

[101] A. Barbato, T. Frischer, C. E. Kuehni, D. Snijders, I. Azevedo, G. Baktai, L. Bartoloni, E. Eber, A. Escribano, E. Haarman, B. Hesselmar, C. Hogg, M. Jorissen, J. Lucas, K. G. Nielsen, C. O'Callaghan, H. Omran, P. Pohunek, M. P. Strippoli, and A. Bush, "Primary ciliary dyskinesia: a consensus statement on diagnostic and treatment approaches in children," Eur Respir J, vol. 34, pp. 1264-76, Dec 2009.

[102] M. Fliegauf, H. Olbrich, J. Horvath, J. H. Wildhaber, M. A. Zariwala, M. Kennedy, M. R. Knowles, and H. Omran, "Mislocalization of DNAH5 and DNAH9 in respiratory cells from patients with primary ciliary dyskinesia," Am J Respir Crit Care Med, vol. 171, pp. 1343-9, Jun 152005.

[103] H. N. Morillas, M. Zariwala, and M. R. Knowles, "Genetic causes of bronchiectasis: primary ciliary dyskinesia," Respiration, vol. 74, pp. 252-63, 2007.

[104] S. D. Sagel, "Nasal nitric oxide: diagnostic value and physiological significance in primary ciliary dyskinesia," J Pediatr, vol. 159, pp. 363-5, Sep 2011.

[105] M. ten Berge, G. Brinkhorst, A. A. Kroon, and J. C. de Jongste, "DNase treatment in primary ciliary dyskinesia--assessment by nocturnal pulse oximetry," Pediatr Pulmonol, vol. 27, pp. 59-61, Jan 1999.

[106] M. Geremek, M. Bruinenberg, E. Zietkiewicz, A. Pogorzelski, M. Witt, and C. Wijmenga, "Gene expression studies in cells from primary ciliary dyskinesia patients identify 208 potential ciliary genes," Hum Genet, vol. 129, pp. 283-93, Mar 2011.

[107] B. Banizs, M. M. Pike, C. L. Millican, W. B. Ferguson, P. Komlosi, J. Sheetz, P. D. Bell, E. M. Schwiebert, and B. K. Yoder, "Dysfunctional cilia lead to altered ependyma and choroid plexus function, and result in the formation of hydrocephalus," Development, vol. 132, pp. 5329-39, Dec 2005.

[108] H. J. Garton and J. H. Piatt, Jr., "Hydrocephalus," Pediatr Clin North Am, vol. 51, pp. 305-25, Apr 2004.

[109] A. Aschoff, P. Kremer, B. Hashemi, and S. Kunze, "The scientific history of hydrocephalus and its treatment," Neurosurg Rev, vol. 22, pp. 67-93; discussion 94-5, Oct 1999. 
[110] T. S. Lim, S. W. Yong, and S. Y. Moon, "Repetitive lumbar punctures as treatment for normal pressure hydrocephalus," Eur Neurol, vol. 62, pp. 293-7, 2009.

[111] I. Ibanez-Tallon, A. Pagenstecher, M. Fliegauf, H. Olbrich, A. Kispert, U. P. Ketelsen, A. North, N. Heintz, and H. Omran, "Dysfunction of axonemal dynein heavy chain Mdnah5 inhibits ependymal flow and reveals a novel mechanism for hydrocephalus formation," Hum Mol Genet, vol. 13, pp. 2133-41, Sep 152004.

[112] C. Wodarczyk, I. Rowe, M. Chiaravalli, M. Pema, F. Qian, and A. Boletta, "A novel mouse model reveals that polycystin-1 deficiency in ependyma and choroid plexus results in dysfunctional cilia and hydrocephalus," PLoS One, vol. 4, p. e7137, 2009.

[113] M. A. Greenstone, R. W. Jones, A. Dewar, B. G. Neville, and P. J. Cole, "Hydrocephalus and primary ciliary dyskinesia," Arch Dis Child, vol. 59, pp. 481-2, May 1984.

[114] J. Zhang, M. A. Williams, and D. Rigamonti, "Genetics of human hydrocephalus," J Neurol, vol. 253, pp. 1255-66, Oct 2006.

[115] S. Weller and J. Gartner, "Genetic and clinical aspects of X-linked hydrocephalus (L1 disease): Mutations in the L1CAM gene," Hum Mutat, vol. 18, pp. 1-12, 2001.

[116] D. S. Bickers and R. D. Adams, "Hereditary stenosis of the aqueduct of Sylvius as a cause of congenital hydrocephalus," Brain, vol. 72, pp. 246-62, Jun 1949.

[117] S. Kenwrick, M. Jouet, and D. Donnai, "X linked hydrocephalus and MASA syndrome," J Med Genet, vol. 33, pp. 59-65, Jan 1996.

[118] I. Ibanez-Tallon, S. Gorokhova, and N. Heintz, "Loss of function of axonemal dynein Mdnah5 causes primary ciliary dyskinesia and hydrocephalus," Hum Mol Genet, vol. 11, pp. 715-21, Mar 152002.

[119] K. F. Lechtreck, P. Delmotte, M. L. Robinson, M. J. Sanderson, and G. B. Witman, "Mutations in Hydin impair ciliary motility in mice," J Cell Biol, vol. 180, pp. 633-43, Feb 112008.

[120] K. F. Lechtreck and G. B. Witman, "Chlamydomonas reinhardtii hydin is a central pair protein required for flagellar motility," J Cell Biol, vol. 176, pp. 473-82, Feb 122007.

[121] A. Ohtoshi, "Hydrocephalus caused by conditional ablation of the Pten or beta-catenin gene," Cerebrospinal Fluid Res, vol. 5, p. 16, 2008.

[122] J. B. Wallingford and B. Mitchell, "Strange as it may seem: the many links between Wnt signaling, planar cell polarity, and cilia," Genes Dev, vol. 25, pp. 201-13, Feb 12011.

[123] C. Gavino and S. Richard, "Patched1 haploinsufficiency impairs ependymal cilia function of the quaking viable mice, leading to fatal hydrocephalus," Mol Cell Neurosci, vol. 47, pp. 100-7, Jun 2011.

[124] L. Jacob and L. Lum, "Deconstructing the hedgehog pathway in development and disease," Science, vol. 318, pp. 66-8, Oct 52007.

[125] V. Varadi, K. Csecsei, G. T. Szeifert, Z. Toth, and Z. Papp, "Prenatal diagnosis of X linked hydrocephalus without aqueductal stenosis," J Med Genet, vol. 24, pp. 207-9, Apr 1987.

[126] D. Greitz, T. Greitz, and T. Hindmarsh, "A new view on the CSF-circulation with the potential for pharmacological treatment of childhood hydrocephalus," Acta Paediatr, vol. 86, pp. 125-32, Feb 1997.

[127] L. Jia, Z. X. Zhao, C. You, J. G. Liu, S. Q. Huang, M. He, P. G. Ji, J. Duan, Y. J. Zeng, and G. P. Li, "Minimally-invasive treatment of communicating hydrocephalus using a percutaneous lumboperitoneal shunt," J Zhejiang Univ Sci B, vol. 12, pp. 293-7, Apr 2011. 
[128] D. M. Sciubba, R. M. Stuart, M. J. McGirt, G. F. Woodworth, A. Samdani, B. Carson, and G. I. Jallo, "Effect of antibiotic-impregnated shunt catheters in decreasing the incidence of shunt infection in the treatment of hydrocephalus," J Neurosurg, vol. 103, pp. 131-6, Aug 2005.

[129] V. E. Torres, P. C. Harris, and Y. Pirson, "Autosomal dominant polycystic kidney disease," Lancet, vol. 369, pp. 1287-301, Apr 142007.

[130] C. R. Halvorson, M. S. Bremmer, and S. C. Jacobs, "Polycystic kidney disease: inheritance, pathophysiology, prognosis, and treatment," Int J Nephrol Renovasc Dis, vol. 3, pp. 69-83, 2010.

[131] R. J. Quinlan, J. L. Tobin, and P. L. Beales, "Modeling ciliopathies: Primary cilia in development and disease," Curr Top Dev Biol, vol. 84, pp. 249-310, 2008.

[132] J. Hoefele, K. Mayer, M. Scholz, and H. G. Klein, "Novel PKD1 and PKD2 mutations in autosomal dominant polycystic kidney disease (ADPKD)," Nephrol Dial Transplant, vol. 26, pp. 2181-8, Jul 2011.

[133] Y. C. Tan, J. D. Blumenfeld, R. Anghel, S. Donahue, R. Belenkaya, M. Balina, T. Parker, D. Levine, D. G. Leonard, and H. Rennert, "Novel method for genomic analysis of PKD1 and PKD2 mutations in autosomal dominant polycystic kidney disease," Hum Mutat, vol. 30, pp. 264-73, Feb 2009.

[134] B. K. Yoder, X. Hou, and L. M. Guay-Woodford, "The polycystic kidney disease proteins, polycystin-1, polycystin-2, polaris, and cystin, are co-localized in renal cilia," J Am Soc Nephrol, vol. 13, pp. 2508-16, Oct 2002.

[135] G. J. Pazour, J. T. San Agustin, J. A. Follit, J. L. Rosenbaum, and G. B. Witman, "Polycystin-2 localizes to kidney cilia and the ciliary level is elevated in orpk mice with polycystic kidney disease," Curr Biol, vol. 12, pp. R378-80, Jun 42002.

[136] A. C. Ong and D. N. Wheatley, "Polycystic kidney disease--the ciliary connection," Lancet, vol. 361, pp. 774-6, Mar 12003.

[137] S. Wang, J. Zhang, S. M. Nauli, X. Li, P. G. Starremans, Y. Luo, K. A. Roberts, and J. Zhou, "Fibrocystin/polyductin, found in the same protein complex with polycystin-2, regulates calcium responses in kidney epithelia," Mol Cell Biol, vol. 27, pp. 3241-52, Apr 2007.

[138] I. Kim, Y. Fu, K. Hui, G. Moeckel, W. Mai, C. Li, D. Liang, P. Zhao, J. Ma, X. Z. Chen, A. L. George, Jr., R. J. Coffey, Z. P. Feng, and G. Wu, "Fibrocystin/polyductin modulates renal tubular formation by regulating polycystin-2 expression and function," J Am Soc Nephrol, vol. 19, pp. 455-68, Mar 2008.

[139] G. J. Pazour, "Intraflagellar transport and cilia-dependent renal disease: the ciliary hypothesis of polycystic kidney disease," J Am Soc Nephrol, vol. 15, pp. 2528-36, Oct 2004.

[140] F. Lin, T. Hiesberger, K. Cordes, A. M. Sinclair, L. S. Goldstein, S. Somlo, and P. Igarashi, "Kidney-specific inactivation of the KIF3A subunit of kinesin-II inhibits renal ciliogenesis and produces polycystic kidney disease," Proc Natl Acad Sci U S A, vol. 100, pp. 5286-91, Apr 292003.

[141] N. Kishimoto, Y. Cao, A. Park, and Z. Sun, "Cystic kidney gene seahorse regulates cilia-mediated processes and Wnt pathways," Dev Cell, vol. 14, pp. 954-61, Jun 2008.

[142] Z. Sun, A. Amsterdam, G. J. Pazour, D. G. Cole, M. S. Miller, and N. Hopkins, "A genetic screen in zebrafish identifies cilia genes as a principal cause of cystic kidney," Development, vol. 131, pp. 4085-93, Aug 2004. 
[143] W. Gronwald, M. S. Klein, R. Zeltner, B. D. Schulze, S. W. Reinhold, M. Deutschmann, A. K. Immervoll, C. A. Boger, B. Banas, K. U. Eckardt, and P. J. Oefner, "Detection of autosomal dominant polycystic kidney disease by NMR spectroscopic fingerprinting of urine," Kidney Int, vol. 79, pp. 1244-53, Jun 2011.

[144] M. A. Garcia-Gonzalez, J. G. Jones, S. K. Allen, C. M. Palatucci, S. D. Batish, W. K. Seltzer, Z. Lan, E. Allen, F. Qian, X. M. Lens, Y. Pei, G. G. Germino, and T. J. Watnick, "Evaluating the clinical utility of a molecular genetic test for polycystic kidney disease," Mol Genet Metab, vol. 92, pp. 160-7, Sep-Oct 2007.

[145] J. M. Shillingford, N. S. Murcia, C. H. Larson, S. H. Low, R. Hedgepeth, N. Brown, C. A. Flask, A. C. Novick, D. A. Goldfarb, A. Kramer-Zucker, G. Walz, K. B. Piontek, G. G. Germino, and T. Weimbs, "The mTOR pathway is regulated by polycystin-1, and its inhibition reverses renal cystogenesis in polycystic kidney disease," Proc Natl Acad Sci U S A, vol. 103, pp. 5466-71, Apr 42006.

[146] N. O. Bukanov, L. A. Smith, K. W. Klinger, S. R. Ledbetter, and O. IbraghimovBeskrovnaya, "Long-lasting arrest of murine polycystic kidney disease with CDK inhibitor roscovitine," Nature, vol. 444, pp. 949-52, Dec 142006.

[147] G. Jia, M. Kwon, H. L. Liang, J. Mortensen, V. Nilakantan, W. E. Sweeney, and F. Park, "Chronic treatment with lisinopril decreases proliferative and apoptotic pathways in autosomal recessive polycystic kidney disease," Pediatr Nephrol, vol. 25, pp. 113946, Jun 2010.

[148] X. Wang, V. Gattone, 2nd, P. C. Harris, and V. E. Torres, "Effectiveness of vasopressin V2 receptor antagonists OPC-31260 and OPC-41061 on polycystic kidney disease development in the PCK rat," J Am Soc Nephrol, vol. 16, pp. 846-51, Apr 2005.

[149] T. V. Masyuk, A. I. Masyuk, V. E. Torres, P. C. Harris, and N. F. Larusso, "Octreotide inhibits hepatic cystogenesis in a rodent model of polycystic liver disease by reducing cholangiocyte adenosine 3',5'-cyclic monophosphate," Gastroenterology, vol. 132, pp. 1104-16, Mar 2007.

[150] P. Ruggenenti, A. Remuzzi, P. Ondei, G. Fasolini, L. Antiga, B. Ene-Iordache, G. Remuzzi, and F. H. Epstein, "Safety and efficacy of long-acting somatostatin treatment in autosomal-dominant polycystic kidney disease," Kidney Int, vol. 68, pp. 206-16, Jul 2005.

[151] W. E. Sweeney, Y. Chen, K. Nakanishi, P. Frost, and E. D. Avner, "Treatment of polycystic kidney disease with a novel tyrosine kinase inhibitor," Kidney Int, vol. 57, pp. 33-40, Jan 2000.

[152] Y. Solak, H. Atalay, I. Polat, and Z. Biyik, "Colchicine treatment in autosomal dominant polycystic kidney disease: many points in common," Med Hypotheses, vol. 74, pp. 314-7, Feb 2010.

[153] J. L. Tobin and P. L. Beales, "Bardet-Biedl syndrome: beyond the cilium," Pediatr Nephrol, vol. 22, pp. 926-36, Jul 2007.

[154] K. Baker and P. L. Beales, "Making sense of cilia in disease: the human ciliopathies," Am J Med Genet C Semin Med Genet, vol. 151C, pp. 281-95, Nov 152009.

[155] P. L. Beales, N. Elcioglu, A. S. Woolf, D. Parker, and F. A. Flinter, "New criteria for improved diagnosis of Bardet-Biedl syndrome: results of a population survey," J Med Genet, vol. 36, pp. 437-46, Jun 1999. 
[156] P. Sen Gupta, N. V. Prodromou, and J. P. Chapple, "Can faulty antennae increase adiposity? The link between cilia proteins and obesity," J Endocrinol, vol. 203, pp. 327-36, Dec 2009.

[157] K. Rahmouni, M. A. Fath, S. Seo, D. R. Thedens, C. J. Berry, R. Weiss, D. Y. Nishimura, and V. C. Sheffield, "Leptin resistance contributes to obesity and hypertension in mouse models of Bardet-Biedl syndrome," J Clin Invest, vol. 118, pp. 1458-67, Apr 2008.

[158] C. Christodoulides, C. Lagathu, J. K. Sethi, and A. Vidal-Puig, "Adipogenesis and WNT signalling," Trends Endocrinol Metab, vol. 20, pp. 16-24, Jan 2009.

[159] P. J. King, L. Guasti, and E. Laufer, "Hedgehog signalling in endocrine development and disease," J Endocrinol, vol. 198, pp. 439-50, Sep 2008.

[160] W. Cousin, C. Fontaine, C. Dani, and P. Peraldi, "Hedgehog and adipogenesis: fat and fiction," Biochimie, vol. 89, pp. 1447-53, Dec 2007.

[161] N. F. Berbari, J. S. Lewis, G. A. Bishop, C. C. Askwith, and K. Mykytyn, "Bardet-Biedl syndrome proteins are required for the localization of $\mathrm{G}$ protein-coupled receptors to primary cilia," Proc Natl Acad Sci U S A, vol. 105, pp. 4242-6, Mar 182008.

[162] N. F. Berbari, A. D. Johnson, J. S. Lewis, C. C. Askwith, and K. Mykytyn, "Identification of ciliary localization sequences within the third intracellular loop of G proteincoupled receptors," Mol Biol Cell, vol. 19, pp. 1540-7, Apr 2008.

[163]J. R. Lupski, N. Katsanis, S. J. Ansley, J. L. Badano, E. R. Eichers, R. A. Lewis, B. E. Hoskins, P. J. Scambler, W. S. Davidson, and P. L. Beales, "Triallelic inheritance in Bardet-Biedl syndrome, a Mendelian recessive disorder," Science, vol. 293, pp. 22562259, Sep 212001.

[164] J. R. Davenport, A. J. Watts, V. C. Roper, M. J. Croyle, T. van Groen, J. M. Wyss, T. R. Nagy, R. A. Kesterson, and B. K. Yoder, "Disruption of intraflagellar transport in adult mice leads to obesity and slow-onset cystic kidney disease," Curr Biol, vol. 17, pp. 1586-94, Sep 182007.

[165] D. L. Simons, S. L. Boye, W. W. Hauswirth, and S. M. Wu, "Gene therapy prevents photoreceptor death and preserves retinal function in a Bardet-Biedl syndrome mouse model," Proc Natl Acad Sci U S A, vol. 108, pp. 6276-81, Apr 122011.

[166] A. L. Negri, F. R. Spivacow, E. E. Del Valle, M. Forrester, G. Rosende, and I. Pinduli, "Role of overweight and obesity on the urinary excretion of promoters and inhibitors of stone formation in stone formers," Urol Res, vol. 36, pp. 303-7, Dec 2008.

[167] L. Garfinkel, "Overweight and mortality," Cancer, vol. 58, pp. 1826-9, Oct 151986.

[168] N. V. Christou, J. S. Sampalis, M. Liberman, D. Look, S. Auger, A. P. McLean, and L. D. MacLean, "Surgery decreases long-term mortality, morbidity, and health care use in morbidly obese patients," Ann Surg, vol. 240, pp. 416-23; discussion 423-4, Sep 2004.

[169] E. Westly, "Fat attack," Sci Am, vol. 303, pp. 20-2, Sep 2010.

[170] L. M. Quarmby and J. D. Parker, "Cilia and the cell cycle?," J Cell Biol, vol. 169, pp. 70710, Jun 62005.

[171] M. Fliegauf, T. Benzing, and H. Omran, "When cilia go bad: cilia defects and ciliopathies," Nat Rev Mol Cell Biol, vol. 8, pp. 880-93, Nov 2007.

[172] E. J. Michaud and B. K. Yoder, "The primary cilium in cell signaling and cancer," Cancer Res, vol. 66, pp. 6463-7, Jul 12006. 
[173] S. Y. Wong, A. D. Seol, P. L. So, A. N. Ermilov, C. K. Bichakjian, E. H. Epstein, Jr., A. A. Dlugosz, and J. F. Reiter, "Primary cilia can both mediate and suppress Hedgehog pathway-dependent tumorigenesis," Nat Med, vol. 15, pp. 1055-61, Sep 2009.

[174] Y. G. Han and A. Alvarez-Buylla, "Role of primary cilia in brain development and cancer," Curr Opin Neurobiol, vol. 20, pp. 58-67, Feb 2010.

[175] R. Rohatgi, L. Milenkovic, and M. P. Scott, "Patched1 regulates hedgehog signaling at the primary cilium," Science, vol. 317, pp. 372-6, Jul 202007.

[176] Y. G. Han, H. J. Kim, A. A. Dlugosz, D. W. Ellison, R. J. Gilbertson, and A. AlvarezBuylla, "Dual and opposing roles of primary cilia in medulloblastoma development," Nat Med, vol. 15, pp. 1062-5, Sep 2009.

[177] K. Yuan, N. Frolova, Y. Xie, D. Wang, L. Cook, Y. J. Kwon, A. D. Steg, R. Serra, and A. R. Frost, "Primary cilia are decreased in breast cancer: analysis of a collection of human breast cancer cell lines and tissues," J Histochem Cytochem, vol. 58, pp. 85770, Oct 2010.

[178] A. J. Bowers and J. F. Boylan, "Nek8, a NIMA family kinase member, is overexpressed in primary human breast tumors," Gene, vol. 328, pp. 135-42, Mar 172004.

[179] M. R. Mahjoub, M. L. Trapp, and L. M. Quarmby, "NIMA-related kinases defective in murine models of polycystic kidney diseases localize to primary cilia and centrosomes," J Am Soc Nephrol, vol. 16, pp. 3485-9, Dec 2005.

[180] A. Jemal, R. Siegel, E. Ward, Y. Hao, J. Xu, T. Murray, and M. J. Thun, "Cancer statistics, 2008," CA Cancer J Clin, vol. 58, pp. 71-96, Mar-Apr 2008.

[181] C. Almoguera, D. Shibata, K. Forrester, J. Martin, N. Arnheim, and M. Perucho, "Most human carcinomas of the exocrine pancreas contain mutant c-K-ras genes," Cell, vol. 53, pp. 549-54, May 201988.

[182] E. S. Seeley, C. Carriere, T. Goetze, D. S. Longnecker, and M. Korc, "Pancreatic cancer and precursor pancreatic intraepithelial neoplasia lesions are devoid of primary cilia," Cancer Res, vol. 69, pp. 422-30, Jan 152009.

[183] K. Pickert, "Screening dilemma. Are some cancers better left undiscovered?," Time, vol. 177, pp. 60-4, 67, Jun 132011. 


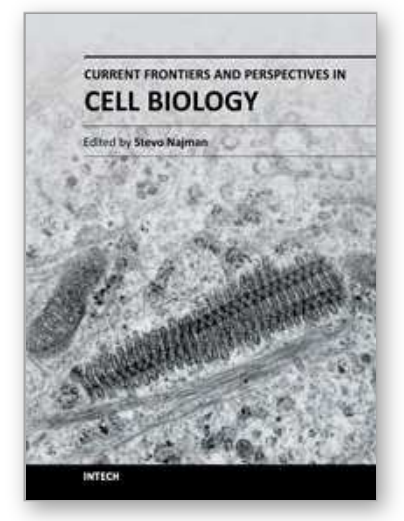

\section{Current Frontiers and Perspectives in Cell Biology \\ Edited by Prof. Stevo Najman}

ISBN 978-953-51-0544-2

Hard cover, 556 pages

Publisher InTech

Published online 25, April, 2012

Published in print edition April, 2012

\section{How to reference}

In order to correctly reference this scholarly work, feel free to copy and paste the following:

David Alejandro Silva, Elizabeth Richey and Hongmin Qin (2012). Biology of Cilia and Ciliopathies, Current Frontiers and Perspectives in Cell Biology, Prof. Stevo Najman (Ed.), ISBN: 978-953-51-0544-2, InTech, Available from: http://www.intechopen.com/books/current-frontiers-and-perspectives-in-cell-biology/biology-ofcilia-and-ciliopathies

\section{INTECH}

open science | open minds

\section{InTech Europe}

University Campus STeP Ri

Slavka Krautzeka 83/A

51000 Rijeka, Croatia

Phone: +385 (51) 770447

Fax: +385 (51) 686166

www.intechopen.com

\section{InTech China}

Unit 405, Office Block, Hotel Equatorial Shanghai

No.65, Yan An Road (West), Shanghai, 200040, China 中国上海市延安西路65号上海国际贵都大饭店办公楼 405 单元

Phone: +86-21-62489820

Fax: $+86-21-62489821$ 
(C) 2012 The Author(s). Licensee IntechOpen. This is an open access article distributed under the terms of the Creative Commons Attribution 3.0 License, which permits unrestricted use, distribution, and reproduction in any medium, provided the original work is properly cited. 